Portland State University

PDXScholar

2-21-1995

\title{
Silence: A Comparison of Japanese and U.S. Interpretation
}

Mimi Murayama

Portland State University

Follow this and additional works at: https://pdxscholar.library.pdx.edu/open_access_etds

Part of the Speech and Rhetorical Studies Commons Let us know how access to this document benefits you.

\section{Recommended Citation}

Murayama, Mimi, "Silence: A Comparison of Japanese and U.S. Interpretation" (1995). Dissertations and Theses. Paper 4935.

https://doi.org/10.15760/etd.6811

This Thesis is brought to you for free and open access. It has been accepted for inclusion in Dissertations and Theses by an authorized administrator of PDXScholar. Please contact us if we can make this document more accessible: pdxscholar@pdx.edu. 
The abstract and thesis of Mimi Murayama for the degree in Master of Arts in Speech Communication were presented February 21, 1995, and accepted by the thesis committee and the department.

COMMITTEE APPROVALS:

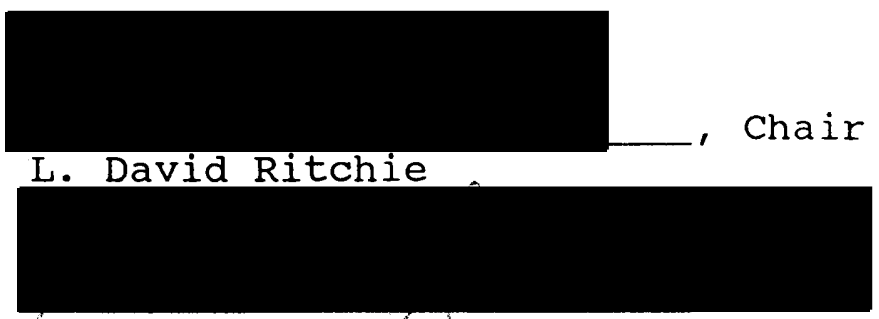

Devorah Lieberman
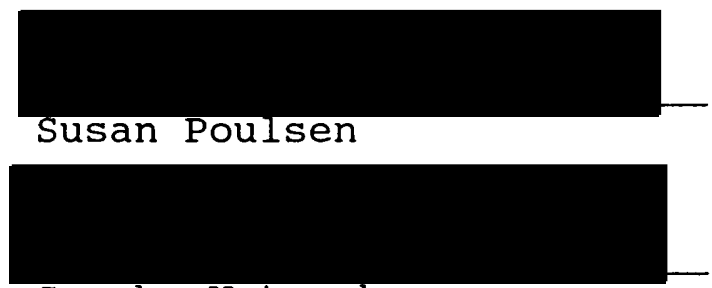

Suwako Watanabe

Representative of the office of Graduate studies

DEPARTMENT APPROVAL:

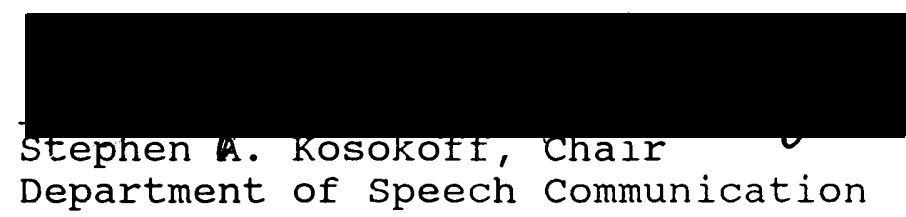

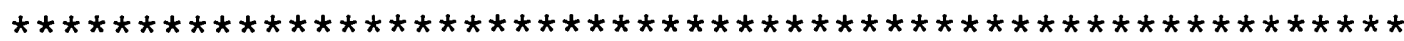
ACCEPTED FOR PORTLAND STATE UNIVERSITY BY THE LIBRARY by

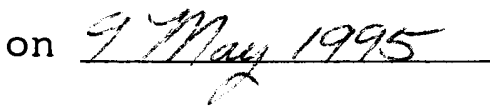




\section{ABSTRACT}

An abstract of the thesis of Mimi Murayama for the Master of Arts in Speech Communication presented February 21, 1995.

Title: Silence: A Comparison of Japanese and U.S. Interpretation

It is commonly argued that silence is an important Japanese communication strategy, with the goal of making oneself understood without words; on the other hand, in the U.S., silence tends to be filled by speaking, and speaking up clearly and the facilitation of talking is preferred.

However, our knowledge about how silence is interpreted in the U.S. and Japan is weak and based on anecdotal evidence. Therefore, this study examines how people in the U.S. and Japan interpret silence according to contexts, examining what kinds of social rules underlie their interpretation.

Interpretation is guided by how people connect ideas. One of the ways to observe how people connect ideas is to have subjects sort words related to silence and compare the way they arrange the words into groups. Multidimensional scaling was used to estimate the underlying dimensions in the way each group sorts the words, and then these dimension were compared. 
In the comparison of how Japanese and the U.S. associate words related to silence, the most significant difference between Japanese and U.S. subjects was found in the way subjects associate groups of words with contexts. The U.S. subjects had a tendency to interpret silence more positive than Japanese in most contexts. Japanese revealed the tendency to interpret silence more active than the U.S. subjects in most contexts.

For Japanese, silence has particular symbolic meaning, and the communicator is often expected to figure out the underlying meaning of silence. When silence is used to intentionally communicate something, it can create uncertainty if the listener is unable to figure what underlies the silence. In U.S., silence is interpreted as positive and less active, that is to say, more internal and reflective.

In conclusion, the findings suggest that Japanese interpret silence as a communicative symbol that must be actively interpreted, and this is consistent with most literature, however, they emphatically contradict the stereotype of "vocal Americans", commonly depicted in the literature. 
SILENCE: A COMPARISON OF

JAPANESE AND U.S. INTERPRETATION

by

MIMI MURAYAMA

A thesis submitted in partial fulfillment of the requirements for the degree of

\author{
MASTER OF ARTS \\ in \\ SPEECH COMMUNICATION
}

Portland State University

1995 


\section{ACKNOWLEDGMENTS}

First and foremost, I want to express deep gratitude to my advisor, Dr. David Ritchie. He was always available to answer any questions in a very lucid and comprehensive way. His advice helped me in conducting data analysis and interpreting results. I also want to express my warm appreciation to Dr. Devorah Lieberman, and Dr. Susan Poulsen in leading me to the proposal meeting. Their views of cross-cultural communication were valuable and helpful in putting my review of literature together.

This study owes much to the support of various other people. Wes Brenner, a system Analyst II, struggled successfully with technical problems. Prof. Hajime Sakai at Sano Women University, Prof. Motofusa Murayama at Chiba University, and various Japanese cultural organizations in the portland area provided me with subjects for my research. Dr. Suwako Watanabe, Gretchen Gear, Linda and steve Gifford supported me in clarifying thoughts and language.

Furthermore, I want to thank my parents, my cousins: Masuo and Chieko Saito for their emotional and financial support. They were very patient, believed in me, and didn't give up on me. Finally I could not have completed this work without help from my best friends, Bill Gear, 
iii

Nina Murayama, and Naomi Morita. Each in their own distinct way, supported me and made me feel at home away from home. 
ACKNOWLEDGEMENTS $\ldots \ldots \ldots \ldots \ldots \ldots \ldots \ldots \ldots \ldots \ldots \ldots \ldots$

LIST OF TABLES $\ldots \ldots \ldots \ldots \ldots \ldots \ldots \ldots \ldots \ldots \ldots \ldots$

LIST OF FIGURES .................... vii CHAPTER

I $\quad$ PREFACE $\ldots \ldots \ldots \ldots \ldots \ldots \ldots \ldots \ldots \ldots \ldots \ldots \ldots \ldots \ldots \ldots$

Introduction .............. 1

Purpose $\ldots \ldots \ldots \ldots \ldots \ldots \ldots \ldots \ldots$

Significance and Justification .... 3 of this study

II LITERATURE REVIEW ............... 6

Definition of Interpretation ..... 6 and Meaning

Theories of Communication ....... 8

Interpretation and .......... 13

Functions of Silence

Hypotheses ................ 46

III $\operatorname{METHODS} \ldots \ldots \ldots \ldots \ldots \ldots \ldots \ldots \ldots$

Procedure .................. 54

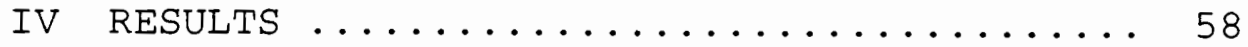

Subjects' Characteristics ....... 58

Summary of Results ............ 78

V DISCUSSION AND CONCLUSION ........... 83

Discussion ................. 84

Threats to Validity ............. 111 
Future Research ............... 113

Summary of Findings .......... 116

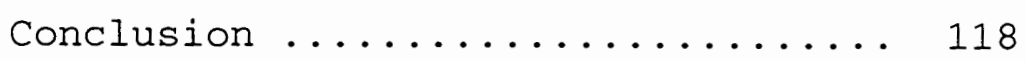

REFERENCES CITED ....................... 122 APPENDICES

A QUESTIONNAIRE (THE U.S.) ............. 133

B KEY WORDS FOR CARDS SORT (THE U.S.) .... 137

C TEN CONTEXTS (THE U.S.) ..................139

D QUESTIONNAIRE (JAPANESE) .............. 141

E KEY WORDS FOR CARDS SORT (JAPANESE) .... 145

F TEN CONTEXTS (JAPANESE) ............ 147 


\section{LIST OF TABLES}

TABLE

PAGE

I Subjects Gathered .............. 59

II Subjects Used for the Study ........ 59

II $\quad$ Subjects Experienced Tea Ceremony .....6 60

IV Subjects Experienced Calligraphy .....6 60

V Subjects Experienced ............. 60

Flower Arrangement

VI Subjects Experienced Karate .........60 60

VII Education by Nationalities ........ 62

VIII Major by Nationalities ............ 62

IX Subjects' Weights ............666

X Average Overall Interpretation ...... 68 of Silence

XI Mean Dimension Scores Associated ..... 69 with Each Context

Context $1 \ldots \ldots \ldots \ldots \ldots \ldots \ldots \ldots$

Context $2 \ldots \ldots \ldots \ldots \ldots \ldots \ldots$

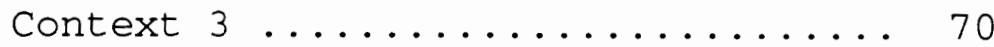

Context $4 \ldots \ldots \ldots \ldots \ldots \ldots \ldots$

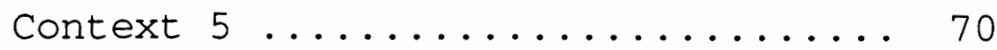

Context $6 \ldots \ldots \ldots \ldots \ldots \ldots$

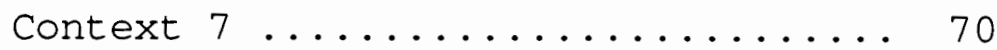

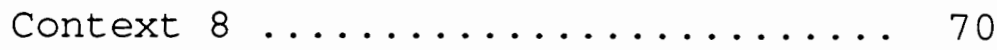

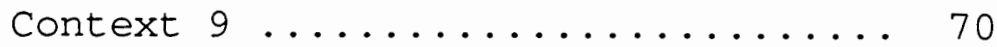

Context $10 \ldots \ldots \ldots \ldots \ldots \ldots \ldots \ldots$ 


\section{LIST OF FIGURES}

FIGURE

PAGE

1. The Minimum Communication Model ....... 6

2. Hierarchy of Contexts .............. 11

3. Multidimensional Scaling: All subjects .. 64

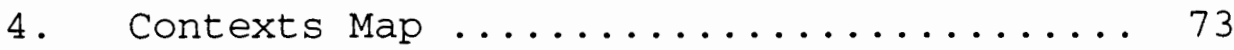

5. Multidimensional Scaling: Japanese .....75

6. Multidimensional Scaling: Americans .....76

7. Bar Graph of Comparing Mean Dimension ... 80 Score between Japanese and the U.S. context 1: Discussing Holiday

8. Bar Graph of Comparing Mean Dimension ... 80 Score between Japanese and the U.S. Context 2: Negotiating with Teacher

9. Bar Graph of Comparing Mean Dimension ... 80 Score between Japanese and the U.S. context 3: Silence of Your Partner

10. Bar Graph of Comparing Mean Dimension ... 80 Score between Japanese and the U.S. context 4: Silence of Your Boss

11. Bar Graph of Comparing Mean Dimension ... Score between Japanese and the U.S. context 5: Silence of Your Parents.

12. Bar Graph of Comparing Mean Dimension ... 81 Score between Japanese and the U.S. context 6: Silence of Your Teacher

13. Bar Graph of Comparing Mean Dimension ... 81 Score between Japanese and the U.S. context 7: Silence of Your Friend

14. Bar Graph of Comparing Mean Dimension ... 81 Score between Japanese and the U.S. context 8: Silence when You Are Alone

15. Bar Graph of Comparing Mean Dimension ... 81 
viii

Score between Japanese and the U.S. Context 9: Silence of Your Japanese Friends

16. Bar Graph of Comparing Mean Dimension ... 81 Score between Japanese and the U.S. Context 10: Silence when Practicing Japanese Arts 
CHAPTER I

PREFACE

INTRODUCTION

There is an increasing amount of interaction among people of different cultural backgrounds. Business contacts between Japan and the U.S. are becoming very common (Sullivan \& Kameda, 1982). When Japanese and people from the U.S. have problems communicating with each other, it is often said; "Since Japanese people don't explain their opinions or situations clearly enough with words, they are ignored by foreigners" (Naotsuka, 1992, p. 29). Communication breakdowns among Japanese and people from the U.S. may happen because the Japanese use their own communication styles and people from the U.S. use their own. As Condon and Yousef (1975) mention; "the structural process of communication is considered differently by different people" (p. 32).

Communication is contextual and rule-governed (Shimanoff, 1980). Depending on the context, people behave differently and ways people communicate varies according to their culturally embedded rules and values which they have learned (Samovar and Porter 1991). One may ask, how can Japanese communicate better with people from the U.S. and vise versa? 
PURPOSE

The purpose of this research is to study interpretations of silence between Japanese and U.S. subjects and promote understanding of (a) Japanese and U.S. communication patterns, and (b) their respective value and rules. In the communication literature, most of the discussion on silence and its function in communication is anecdotal, and not much empirical study has been conducted regarding silence. Moreover, our knowledge about how silence in interpreted in the U.S. and Japan is weak and based on anecdotal evidence. Discussing culturally specific interpretations of silence without sufficient empirical study may simply reinforce misunderstandings and negative stereotypes. Therefore, this study examines how U.S. and Japanese subjects interpret silence according to situation and relationship contexts.

Furthermore, the researcher considers the U.S. acculturation process by studying typical silence-centered Japanese cultural practices such as; tea ceremony, flower arrangement, Japanese calligraphy, and karate. The researcher studied this by comparing interpretations of silence of people from the U.S. Who have and have not learned the Japanese cultural practices. 
This research defines silence as: a meaningful moment in a flow of communication. Silence is considered as a phenomenon which can be interpreted in various ways, depending on the context and people communicating (Bolton, 1990). Silence gives the interactant time to think and enables him/her to go deeper into himself/herself (Bolton, 1990).

SIGNIFICANCE AND JUSTIFICATION OF THIS STUDY

Silence is discussed as a significant communicative resource and, like talk, it is patterned in culturally significant ways (Braithwaite, 1990). Since the interpretation of silence is culturally specific (Johannesen, 1974; Saville-Troike, 1985; Tannen, 1985), cross-cultural communication studies of silence offer an important insight into communication patterns, characteristics of communication strategies, philosophy, values, and societal rules associated with silence.

Silence is an important Japanese communication strategy, with a goal of making oneself understood without words. A common strategy of silence is the use of pauses between turns at talk, indicative of polite avoidance of interruption (Lebra, 1987). On the other hand, in the U.S., people tend to fill in silence by speaking (Graham \& Herberger, 1983; Ishii \& Bruneau, 1991). Speaking up 
clearly and the facilitation of talking is preferred in the U.S. (Nishida, 1989). This is one of the significant differences between Japanese and U.S. communication strategies: silence is utilized vs silence needs to be filled in; silence vs speaking.

If people from Japan and the U.S. have different interpretation of silence, misunderstandings are likely to occur when Japanese remain silent with carrying a conversation with someone from the U.S. Therefore, the study of interpretations of silence among subjects from Japan and the U.S. may lead us to understand how U.S. and Japanese subjects interpret the same symbolic phenomenon and what kind of values and rules underlie the interpretation.

There are two additional reasons why studying silence between people from Japan and the U.S. is important: first, silence is as important as speaking. Silence can be viewed much the same way as talk (Braithwaite, 1981, p. 2) and it has a similar value in speech (Saville-Troike, 1985). Second, from a linguistic perspective, silence may have been viewed as an absence of sounds (Bruneau, 1973; Johannesen, 1974; Weisman, 1955) and not enough in-depth examination on culturally specific interpretation of silence has been done. Therefore, this study may be able to contribute to an under-researched area in the empirical 
study of silence in human communication research. 
CHAPTER II

LITERATURE REVIEW

DEFINITION OF INTERPRETATION AND MEANING

\section{Interpretation}

This study defines interpretation as "an attempt to explain actions in terms of their meanings" (Littlejohn, 1989, p. 134). Interpretation is a function in processing communication, and it is guided by how people connect ideas. Littlejohn (1989) notes;

$$
\begin{aligned}
& \text { Human beings use symbols in their } \\
& \text { communication... The symbol is interpreted by } \\
& \text { the receiver which makes meaning central to } \\
& \text { social life (Littlejohn, 1989, p. 98). }
\end{aligned}
$$

Human communication includes encoder, message, and decoder according to the minimum communication model created by Markel. In this communication model (figure 1), the process of decoding is called 'interpretation' (Markel, 1969).

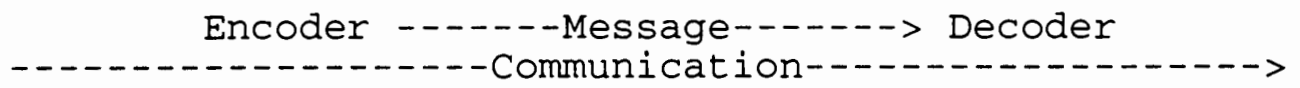

Figure 1. The Minimum Communication Model (Markel, 1969, p.4).

Four concepts are defined as follow;

Encoder - the originator of a message.

Message - Any response of an encoder which may be the stimulus of decoder. 
Decoder - The recipient of a message.

Communication - When a response of an encoder is received as a stimulus for a decoder. (Markel, 1969, p. 3).

When a decoder gets a message as a symbol, he/she interprets the message. In this study, the communicators will be referred to as "sender" and "receiver", although it is recognized that the "sending" and "receiving" metaphor is misleading.

\section{Meaning}

Meaning is explained as the idea which is intended to be understood (Longman Contemporary English Dictionary, 1978). When a message is sent to a receiver intentionally, the message has a meaning and the receiver interprets a meaning. It is important to note that when a message is sent, the receiver does not necessarily interpret the message as it is meant. Littlejohn (1989) states;

Meaning will vary as different people come to make different associations among signs or sign systems and the referents of those signs ( $p$. 52).

Meaning intended by a sender and meaning interpreted by a receiver may be different. There is a possibility to have a double meaning for a message. Therefore, the researcher defines a meaning as that which is interpreted by a person who receives the message. 
THEORIES OF COMMUNICATION

\section{culture and cross cultural communication}

Culture can be defined as:

an identifiable group with shared beliefs and experiences, feelings of worth and value attached to those experiences, and a shared interest in a common historical background (Brislin, 1981, p. 2).

Culture is discussed as an "integrated system of learned behavior patterns which are characteristic of the members of a society and which are not the result of biological inheritance" (Hoebel \& Frost, 1976. p. 6). Kroeber and Kluckhohn (1952. p. 181.) defined culture as a coherence of explicit and implicit patterns of behavior, acquired by symbols, "constituting the distinctive achievement of human groups", including their historical ideas and attached values. The concept of culture may be summarized as the deposit of knowledge, experience, values, attitudes and a concept of the universe acquired by "a group of people in the course of generations through individuals and group striving" (Samovar et al., 1991, p. 51).

Cross cultural study uncovers differences or similarities of communication in relationship patterns across cultures (Ting-Toomey, 1991). Asante and Gudykunst (1989) describe cross cultural communication as "a 
comparison of patterns of interpersonal communication across culture" (p. 9).

All communication is cross cultural communication in one sense (Work, 1981). Differences and similarities in communication patterns are found because self-identity of one's characteristics are anchored in those belief systems, world views, behavioral repertories and cognitive classification systems which are acquired through one's upbringing and socialization within one's culture (Paige \& Martin, 1982) .

Attribution Theory

Attribution theory addresses the ways people infer the causes of behavior. According to Heider (1952), this theory focuses on understanding the manner in which people assign meaning to the events they observe. It explains the process of how people come to understand their own behavior and that of others (Littlejohn, 1989). Attribution theory has three basic assumptions: first, people attempt to determine the causes of behavior; second, people assign causes systematically; third, the attributed cause has impact on the perceiver's own feelings and behavior (Kelley, 1972).

When two people from different cultural backgrounds encounter each other, they attribute their partner's behaviors according to their own perceptions acquired from 
their own culture. Ehrenhaus (1983) argues that in an inter-cultural communication situation, where two people from different cultures meet, converse, and attempt to accomplish a same social task, they use their knowledge acquired from their own culture. This knowledge includes the expectations for interpreting social actions (Ehrenhaus, 1983). Therefore, they may have different expectations for interpreting social actions, having a particular attribution.

Ehrenhaus (1983) states that interpersonal coherence is possible if each attributor structures "the continuous stream of communication similarity" (p. 261), whereas interpersonal coherence may be "lost repeatedly throughout interaction" (p. 261) regardless of using the attempt to accomplish a social task, if communicators make a different attribution about the identical situation.

\section{Rules Theory}

Rules theory states that human behavior is based on the rules of the culture which each person belongs to (Nishida, 1989). Shimanoff (1980) defines a rule as a followable prescription that indicates which behavior is preferred or prohibited in a certain context. Pearce and Cronen (1980) developed the concept of Coordinated Management of Meaning. Two types of rules are discussed in CMM; one is constitutive rules and the other is 
regulative rules. Constitutive rules are rules of meaning used by communicators to interpret or understand the event (Pearce et al., 1980). Regulative rules are rules of action used to determine how to respond or behave (Pearce et al., 1980).

"Rules of meaning and action are always chosen within a context" (Littlejohn, 1989, p. 124). Context is viewed as a hierarchy (see figure 2). Each context itself is examined as a part of a larger context. The order of each context is not universal and interchangeable, i.e., one's action may be understood within the context of an episode (Pearce et al., 1980).

\section{Archetype}

Self-concept

Episode

Relationship

Act

Figure 2. Hierarchy of Contexts (Littlejohn, 1989, p. $124)$.

Littlejohn (1989) presents a hierarchy of contexts adapted from a model of hierarchically organized meaning which is developed by Pearce and Cronen. (see figure 2). In the figure, Act is related to all four contexts. "The relationship context includes mutual expectation among 
members of group" (Littlejohn, 1989, p. 124). The episode context involves events which are defined by an individual who carries different speech and nonverbal behavior (Littlejohn, 1989; Peace et al., 1980). The self-concept context is one's sense of how to perceive oneself (Littlejohn, 1989; Pearce et al., 1980). Archetype context is the level where an individual punctuates his/her experiences beneath diversity of culture, situation and personality in order to communicate (Pearce et al., 1980).

Acculturation

Acculturation concerns changing attitudes, behaviors, and values (Weinstock, 1974). "Different people experience acculturation in a variety of different subjective ways" (Sermol, 1983, p. 40). Through the process of acculturation, people are encouraged to widen their cultural boundaries (Blackton, 1986). Kim (1982) describes acculturation as "the process of developing communication competence in the host system" (p. 361). Brislin (1981) states that cultural competence involves knowledge of language and the ability to behave appropriately in different situations.

Through interactions, people become competent in understanding values of the host culture (Kim, 1982). In other words, through experiencing and relating to members 
of a host culture, people start to understand how to behave appropriately in different situations.

\section{INTERPRETATION AND FUNCTIONS OF SILENCE}

\section{Linguistic Studies of Silence}

Linguistically, silence has been studied as part of the process of turn-taking, as a hesitation pause, and as a switching-pause (Harrigan, 1985, and McLaughlin, 1984). Harrigan (1985) defines silence as a time interval of at least one second before another person speaks, and functions as the interval between two speakers. According to Harrigan (1985), Yngve defined turn-taking as the rhythmic back and forth flow of conversation that results from the mutual cooperation of both speakers and listeners. McLaughlin (1984) distinguishes between (a) the within-turn silence or hesitation pause, and (b) the post-turn silence known as a switching pause. He states that the former is bounded on either side by currentspeaker talk, whereas the latter is bounded by different speakers on either side. A hesitation pause indicates a change of speaker (McLaughlin, 1984). The duration of switching pauses varies depending on the context; on some occasions, they are perceived as too long and awkward by a speaker or by a listener (McLaughlin, 1984). 
Sometimes speakers hesitate while they are deciding what to say and how to express themselves (Chafe, 1985). People process their ideas in this moment of hesitation, thus hesitation functions as a system: grammatical, syntactic decision making, and lexical semantic decisionmaking (Bruneau, 1973).

Silence can be differentiated only by the intentions and conventions of the speaker; one person's silence is another's pause (Tannen, 1985). The function of pausing is to give the speaker time to think, and the listener time to comprehend. The range of a pause is discussed as a length from milliseconds to minutes (Knapp, 1972). The function of the pause is described as follows;

Pauses seem to be subject to considerable variation based on individual differences, the kind of verbal task, the amounts of spontaneity, and the pressure of the particular social situation (Knapp, p. 169).

The social consequence of pausing is to give the impression of being one sort of person rather than another (Tannen, 1985).

Silence as an Absence of Sound and as communication

Longman dictionary (1984) explains silence as "an absence of sound and the state of not speaking or making a noise". Ehrenhaus (1988) views silence as "the absence of a usable form of symbolic expression" (p. 41). Several scholars discuss silence as an absence of sound or as 
choosing not to talk (Bruneau, 1973; Jaksa \& Stech, 1978; Johannesen, 1974; Weisman, 1955).

silence may be viewed as communication when an interactant attributes meaning to silence (Slavson, 1966). When silence has a meaning to be interpreted, it becomes a way of communicating. Silence of the listener is a communicative action because interactants are co-creators of messages (Scott, 1993). A listener's silence provides the space for speaking and invites others to interpret (Scott, 1993).

Speech and silence function as complementary forms of communication; each acquires significance from the other (Barnlund, 1989). Thus, when speaking is meaningful, silence is enhanced, while at the same time silence promotes opportunity for creative meanings (Scott, 1972). "Every speech ends with silence, and there begins" (Scott, 1972, p 147), "In the said there is always enough unsaid to lend opportunity for extension" (Scott, 1972, p. 155). Silence which Regulates Social Relationship

Silence can be viewed socio-culturally. That is, silence is related to the characteristics of each social order regarding when to be silent and when not to be silent (Bruneau, 1973). The relationship among communicators influences the interpretation given to the silence (Samovar and Porter, 1991). 
In some cultures, silence may function to regulate the relationship in the cultural framework between employee and employer (Saville-Troike, 1985). For example, in the U.S., when employees consider themselves as having lower status than their employers, they may remain silent in front of their bosses. Socio-cultural silence also functions to keep social distance and regulates relationships between people. (Saville-Troike, 1985). For example, in the U.S., when people take a trip by airplane, they may remain silent, and avoid verbal contact with the person sitting next to them (SavilleTroike, 1985). In this situation, silence functions as a way of keeping mental space between two persons. Although they are physically very close to each other, they maintain a social distance by being silent.

\section{Silence in Proverbs}

In spoken languages, silence is often referred to in proverbs. Saville-Troike (1985) points out the culturally defined connotative meanings of silence in proverbs. Proverbs carry different values depending on different speech communities. For example, 'The way your eyes look can say more than your mouth', 'The mouth is the source of disaster', and 'By your mouth you will perish' (Japanese). All of these seem to indicate that verbal language is something not preferable in the Japanese culture. 'The 
squeaky wheel gets the grease', 'A picture is worth a thousand words', 'It is better to say little, than too much' and 'Silence is a virtue' (English). These proverbs are examples of how both speech and silence are positively and negatively valued in both U.S. and Japanese culture. In addition, both Japanese and English share the proverb, 'silence is golden'. This may suggest that some communicative functions of silence may be universal and that the way silence is used as strategy and the meaning attached to that particular use might not vary crossculturally (Braithwaite, 1990, p. 322).

\section{Culturally Specific Interpretation of Silence}

Basso (1990) states as follows:

Although the form of silence is always the same, the function of a specific act of silence - that is, its interpretation by and effect upon other people - will vary according to the social context in which it occurs (p. 305).

Johannesen (1974) states that the roles assigned to silence in communication vary from culture to culture and silence is interpreted differently among different cultures. Each culture has different interpretations of silence, and silence in each speech community has different meanings (Saville-Troike, 1985). 'How silence is meant by the sender' and 'how it is interpreted by the receiver' vary according to different speech communities and situations. This is because components of 
communication are learned and socially patterned by the contexts of social group interaction, and are shared by the members of groups (Robbins, Devoe, \& Weiner, 1978). Interpretation of silence varies depending on the personality, situations and the relationship of communicators. The perceiver is encouraged to interpret silence based on what is vocalized right before it (Saville-Troike, 1985). Quakers experience the holy spirit through a silent gathering and they consider this as the true 'gathering'. In their worship, Quakers consider silence as the highest achievement in which the human spirit is capable of receiving the Holy spirit (Lippard, 1988). Thus, Quakers interpret silence in their worship as the way of experiencing the Holy spirit.

Basso (1990) studies certain aspects of silence in the culture of the Western Apache of eastern Arizona. He argues that "keeping silence is associated with social situations in which participants perceive their relationship vis a vis one another to be ambiguous and/or unpredictable" (p. 81).

Western culture in general views fast talk, and short pauses more positively than speaking slowly and allowing the conversational partner to take a long speaking turn (Jaworski, 1993). When silence is meant to convey a specific meaning, it may be intended as: questioning, 
promising, denying, warning, threatening, insulting, requesting, commanding, or carrying out various kinds of ritual interaction in western culture (Saville-Troike, 1985, p. 6). Silence may be interpreted as hatred, anger, and anxiety (Baker, 1955).

Silence is interpreted as placid or being content that may be experienced between lovers or old friends, where words are unnecessary and silence does not create uneasiness (Baker, 1955). It may function as: the cornerstone of character, the virtue of self-control, courage, patience, and dignity (Johannesen, 1974).

According to Hecht, Anderson, and Ribeau (1990), females may be more comfortable when encountering silence than men. They studied the cultural dimension of nonverbal communication and consider gender as a cultural dimension, stating that females are more attentive to silent, nonverbal cues than male.

Ishii et al. (1991) note that as opposed to generally outspoken western women, many women in eastern culture see their silent role as natural and they cannot imagine speaking out unless violated personally.

For women in eastern cultures, silence may be a source of control (Ishii et al., 1991). For example, Ishikawa's study in 1970 reveals that (a) both Japanese business men and women agree upon the idea that men need 
to be silent in order to be successful in life, and (b) many business women prefer to marry silent men. This study may suggest that silence is powerfully embedded in the Japanese society, has a certain control, and is a preferable concept for the Japanese women. In Japanese communication, when the topic is delicate, or the situation is emotional, utterances are commonly left unfinished, i.e., completed in silence (Saville-Troike, 1982). Japanese speakers tend not to explain everything that they want and expect others to figure out what they mean (Wagatsuma, 1982). Thus, they often make subtle, indirect, or vague statements, leaving their utterances open to be interpreted by others (Wagatsuma, 1984). For example, if a Japanese is asked, 'Going out tonight?', and answers, 'Ah.... (silence) my wife doesn't feel well today so...(silence)', this silence implies that he cannot go out tonight and he wants to reject the invitation without saying 'no' directly.

Silence is embedded in several Japanese cultural practices and performances, especially those influenced by Zen-Buddhism. The tea ceremony, karate, Japanese calligraphy, Noh, Kabuki, and flower arrangement are introduced in the following section as Japanese cultural practices which emphasize silence.

Chanoyu. The concept of silence is cultivated in the 
traditional art of Japan - Chanoyu; the tea ceremony. Chanoyu was developed as a ritual of Zen (Okakura 1929). "Zen-Buddhism is described as transcendental and metaphysics, based on the senses, intuitions, and meditation" (Haglund, 1984, p. 70). It is centered in the liberation of the self and self-enlightenment (Haglund, 1984). "The preparation and drinking tea had been part of Japanese life from early time" (Shimizu \& Rosenfield, 1985, p. 188). In early eras, drinking tea was encouraged among zen ministries and it spread among rulers of the country, the samurai warriors, scholars, and public. The tea room has an alcove (tokonoma) in which to hang calligraphy and for placing a flower arrangement (Shimizu et al., 1985). Since both the calligraphy and the flower arrangement have a significant relationship to the tea ceremony, they will be discussed later.

The philosophy of Chanoyu is characterized by wa (harmony), Kei (respect), Sei (Purity), and Jaku (Tranquility) (Sen Soshitsu, 1966). Through the tea ceremony, the master and guests enjoy a peaceful silent moment and achieve a state where silence pervades their minds (Haga, 1991). The tea room is supposed to be a completely empty space and void of any unnecessary ornaments (Sen Soshitsu, 1986). Okakura (1929) states the purpose of the tea ceremony as follows; 
The master of Chanoyu is supposed to conduct the ceremony naturally and simply; without having any distraction of the harmony of the tea room, without having any sounds which distract the rhythm of things, without having any movements which distract the harmonious atmosphere, and without having any words which distract the unity of space. (p. 39).

As Okakura (1929) states, the key for conducting a tea ceremony is to remain silent without any distractive movements and words.

Calligraphy. Japanese Calligraphy (sho or shodo in Japanese) is the art of writing (Nakata, 1973). Among the Japanese zen teachers, it is the most prominent and elegant manner for expressing a heightened state of spiritual consciousness (Shimizu \& Rosenfield, 1985). Calligraphy writers spend a silent moment to portray their spirits into their writings. Through the silent meditation, they may be able to express their spiritual consciousness powerfully.

Japanese Calligraphy and the tea ceremony (Chanoyu) are closely related. The tea ceremony originated in zen monasteries and Calligraphies written by distinguished Zen monks are hung in the tea room (Shimizu, et al., 1985). These hanging Calligraphies are called Kakemono. Writings of Kakemono are informal and casual, and because of their roughness and personal manner, such writings are aesthetic and valuable (Shimizu, et al., 1985). Kakemono is 
carefully mounted on brocades and lovingly displayed in the tea house (Shimizu et al., 1985). The tea master may wish the guests to read his intention or purpose of having a tea ceremony through this carefully displayed Calligraphy Kakemono. Kakemono may be one of the ways for the tea masters and guests to communicate nonverbally during silent tea ceremony.

Flower arrangement. The Japanese flower arrangement (Ikebana, in Japanese) is also related to the tea ceremony. When the tea ceremony reached its highest development, it strongly influenced the flower art (Averill, 1913). There are rules in the flower arrangement that are influenced by Buddhism. Averill (1913) explains the rules as follow:

The idea of good and evil fortune governs both selections of material and form of arrangement...Red flowers, which are used at funerals, are undesirable...because red is supposed to suggest the red flames of fire. An odd number of flowers is lucky, while even numbers are unlucky and therefore undesirable, and never used in flower arrangement. (p. 36).

Those rules are embedded into flower arrangement and the violation of the rules may imply a silent revenge or nonverbal disagreement against the society which governed the rules.

Nishikawa (1936) stated that the purpose of Japanese flower arrangement is to represent various phases of 
nature by flowers and other natural objects (Nishikawa, 1936). In the beauty of flower arrangement, there is no action to be performed, no word to be spoken because the plants sit or stand silently in a vase. But even so, one can perceive their expressions as manifested in their delicate figures (Nishikawa, 1936). The flower arrangement for a funeral may portray dark sorrow, while the flower arrangement for a wedding expresses joy and happiness. A flower arrangement may be a way of communication without vocalizing words. People may see various expressions and feelings through flower arrangements, especially while observing and appreciating the beauty of the flower during a silent moment. And the open space in the arrangement may be equated with silence in a conversation.

Karate. Karate is one of a number of combative arts that have been practiced throughout the history of Japan (Rielly, 1989). The practice of Karate utilizes emptyhanded fighting technique and silence. Karate has a deep relationship with Zen. Oyama (1973) notes, "Zen is karate and karate is zen" (p. 320). In Karate, you must forget yourself, forget winning or losing, and when you have achieved this, you will be in a spiritually unified state, the state of impassivity (Oyama, 1973). This spiritual unification requires no words and no theories, all one 
needs is concentrating one's mind to one thing (Oyama, 1973). Achieving a state of impassivity is zen, and the most important strategy to achieve this state is to keep the body still and silent (Oyama, 1973). Having a silent moment is the key in the spirit of Karate.

Kabuki theater. Kabuki theater has a strong international reputation among Japanese theatrical forms (Brandon, Malm, and Shively, 1979). This is because of the richness of its costumes and the melodrama of its actions and emotions (Brandon, et al., 1979). Kabuki portrays several dimensions of Japanese society. One of the dominant conflicts shown in Kabuki is loyalty to superior ranking personnel and to complicated family ties (Brand, et al., 1979). By engaging loyalties and obligations, characters in Kabuki come into conflict with unexpected personal desires of sympathetic impulses (Brandon, et al., 1979). The characters are captured by the ethical code which governs society and are not allowed to question the code (Brandon et al., 1979). They have to remain silent although they may have a conflict with the code. Perhaps they are forced to be silent so that they can adjust to the social and cultural rule. During the silent period, when performers freeze, audiences observe a peak of emotional intensity (Lebra, 1987).

Noh drama. Silence is utilized in Noh drama. In Noh 
drama, audiences can see only one facial expression from the actors because they are wearing masks. Keene (1990) states that "the characters in the Noh plays are hardly more than beautiful shadows, the momentary embodiments of great emotion" (p. 9).

Performance of Noh demands participation of both stage actors and the audience (Keene, 1990; Sekine, 1985). The purpose of Noh is 'entertainment', and it gives pleasure in proportion to what the audiences give in appreciation (Keene, 1990). One of historically famous Noh directors, Ze-Ami explains how to grasp the attention of the audience:

At an actual performance one usually has a chance to start singing.... Once one thinks that they are waiting for the performance, one should start singing.... If you start singing after the audience sits back, you have missed the opportunity to capture its full attention...(Ze-Ami and Zenchiku, 1974, p. 89).

Performers must sense the precise moment to sing, in accordance with the audiences' expectations (ze-ami, et al., 1974). In order to succeed in a performance, actors must have the ability to anticipate an audience's expectations. This is an example of silent as communication. When the actor chooses the precise moment to sing, the audience will be moved, because their expectations are satisfied. 
Keene (1990) sated that "the Noh plays are admired because they capture in words, music and dance the tragic climaxes of profound emotions" (p. 16). One of the most emotional parts of a Noh play is the silent moment when the actor stops his motion and stops speaking (Keene, 1990). During the pause / silent interval, the audience may understand and feel the actors' profound emotions most vividly.

U.S. Cultural Values and U.S. Communication Styles

The United States of America is a country of immigrants who have diverse linguistic, cultural, and philosophical backgrounds (Okabe, 1983; Yoshikawa, 1982). In this culturally diverse society, all participants in a conversation are responsible for their own opinions, and it is expected that ideas are exchanged verbally (Ramsey et al., 1983). The lack of shared assumptions causes the U.S. speaker to verbalize his/her message in order to make his/her intent clear (Okabe, 1984). Being explicit is the preferred pattern of communication (Hall \& Whyte, 1979; Ishii \& Bruneau, 1991; Yoshikawa, 1982). The pause after one's statement or as a part of on-going dialogue with another is not considered to be consequential (Mare, 1990; Naotsuka, 1992; Yoshikawa, 1982).

For most of the U.S., the ultimate purpose of communication is pragmatic and it is oriented toward cause 
and effect and linear determinism (Ramsey et al., 1983). This means that people tend to explain effects by saying something such as ' $\mathrm{X}$ happened because of $\mathrm{Y}$ '. The U.S. logic tends to be 'getting to the point - strategy' rather than 'beating around the bush - strategy'. Okabe (1983) argues that;

Americans value logical consistency, or line logic, in contrast to.....point logic practiced by Japanese... Americans have a tendency to show greater preference of logos, reason, and cognition whereas the Japanese have a tradition of highly developed words for expressing sympathy, appreciation, and encouragement ( $\mathrm{p}$. 32 ).

Expressing a contradictory opinion to an interactant doesn't necessarily offend the other in the U.S. (Kato and Rozman, 1991). This may be possible because most U.S. people tend to distinguish between a person's words and the person saying them, whereas people's words tend to be taken personally as an expression of the person among Japanese (Ramsey et al., 1983).

In U.S. culture, individualism emphasizes the individual while accepting affiliations within a group (Stewart, 1971). Each individual who is independent and who carries his/her identity interacts with others by expressing his/her own 'view' (Midooka, 1990). In expressing one's own 'view', equality of participants, freedom from social coercion, suspension of privilege, and 
free expressions of feelings are required (Burton \& Kline, 1979). 'What was said' is meaningful and it is not common to try to figure out what may be behind the 'word' of the speaker in the U.S. culture (Kato et al., 1991). Thus U.S. communication tends to depend on verbal expression and utilizes verbalizations as the tool to explain feelings and thoughts (Kato et al., 1991).

Barnlund (1989) states that in the U.S., people tend to view silence as a communicative failure or evidence of a deteriorating relationship. He suggests that this view may come from the fact that democratic societies emphasize an active life over a contemplative life in which (a) doing is more highly valued than being, (b) activity is more valued than inactivity, and (c) talking is more valued than thinking. Condon (1975) suggests that doingoriented societies tend to regard silence as an absence of words or as a waste of time.

Cambra, Ishii and Klopf (1978) examined predispositions toward verbal behavior and found that compared to Japanese, (a) the U.S. subjects were significantly more dominant in conversation, (b) spoke longer, (c) initiated and maintained conversation, (d) were more inclined to talk, and (e) their conversations flow much better than Japanese conversations. However when Klopf repeated this study in 1991, he found that 
(a) the U.S. subjects were only significantly more dominant in conversation and (b) were more inclined to talk (Klopf, 1991). Klopf's study in 1991 may suggest the following; compared to Japanese, (a) in the U.S., people do not necessarily speak longer, (b) are not necessarily better able to initiate and maintain conversation, and (c) are not necessarily more fluent. Getting different results from the same study in 1978 and 1991 may imply that (a) the population was different, (b) the instrument wasn't adequate or (c) communication strategies among people in the contemporary U.S. and/or Japan are changing. People in U.S. may be getting less vocal and less verbal or Japanese may be getting more vocal and more verbal. Japanese Cultural Values and Japanese Communication Styles The nature of Japanese society and culture is that of homogeneity (Okabe, 1983) and in-group cohesiveness (Bieda, 1970). Because of the homogeneity of Japanese culture, Japanese tend to understand each other without verbal communication and they have developed abundant nonIinguistic codes (Tsujimura, 1977). They tend to assume shared communicative situations, i.e., what is appropriate behavior in a certain situation (Midooka, 1990). Words are thought to be deceptive, and silent intuition is one way to interact with the world (Barnlund. 1989). Therefore, Japanese are dubious about the power of words, 
and they resist spelling things out, or explaining themselves (Johnston, 1980).

Japanese culture is known as a nonverbal culture where people utilize 'ma' (silent space or interval) in their conversations. (Mare, 1990; Minami, 1989; Naotsuka, 1992; Pilgrim, 1986). The word 'ma' basically means an interval between two things or events (Pilgrim, 1986). 'Ma' forms the concept of silence (Mare, 1990). Contemporary European language conveys strong-weak, or long-short intonations and is rhythmical in and of itself (Betsumiya, 1983). In contrast, Japanese do not use a system of stress and intonation in their speech, so there is a need of 'ma' in order to create rhythm (Betsumiya, $1983)$.

The concept of 'ma' affects the Japanese communication process in several ways (Mare, 1990, Minami, 1989). First of all, Japanese people tend to expect others to understand what they mean without being explicit. Their communication patterns are characterized by ishin-denshin, haragei, and sasshi. Ishin-denshin (intuitive sense) refers to catching on quickly to another's intention or desire before the thought is completely expressed verbally (Ramsey, 1985). Haragei (hara, belly, and gei art) refers to wordless communication used when the topic is delicate and the 
speaker can't find the words (Saville-Troike, 1985). It is understood as heart-to-heart communication, guessing the inner thoughts of the other by nonverbal means (Ramsey \& Birk, 1983). Sasshi means to surmise or guess (Ramsey, 1985).

These concepts reflect particular meanings of silence in Japanese communication which are positively valued in Japanese culture. Nonverbal intuitive communication practices such as sasshi, haragei and ishindenshin lead to non-confrontational and non-dialectical oriented interpersonal relations among Japanese people (Ishii \& Bruneau, 1991). They believe directness insults the interactants by implying that he/she is insensitive to the nuance of a speakers' message (Johnston, 1980).

The language structure of Japanese is quite different from that of English. In Japanese, the verb comes at the end of the sentence (Ramsey et al., 1983). This allows the speaker to be obscure because he/she can change his/her point while speaking and he/she can consider what is appropriate to say (Doi, 1988). The language may not be based on deliberate and structured thinking patterns (Nakamura, 1964) and it seems to be formulated according to the mood of the speaker (Haglund, 1984). Hall \& Whyle (1979) mention that in some cultures, words and their meanings do not have a direct connection. In this case, 
communicators may be more concerned with the emotional context of the situation than with the meaning of particular words (Hall et al., 1977).

In Japanese communication patterns, events are not separated from relationships, and ideas are not separated from individuals (Ramsey et al., 1983, p. 254). Consequentiy, Japanese try to avoid direct confrontation in communication. Japanese think that direct expressions of emotions or explicitly stating an opinion may bring more negative than positive effects if the relationship is their primary concern (Ramsey, 1985). As Becker (1986) states, the Japanese place higher value on not offending others than speaking clearly, and silence is preferred to verbal response. They remain silent when they want to avoid conflict and embarrassment and to save face (Graham et al., 1983). Directness may mean rudeness for Japanese (Hoshi, 1987).

Yamada (1989) studied U.S. and Japanese topic management strategies by examining two nonverbalized systems; (a) the turn-taking system; and (b) the pausing system. In her study, the pausing system is defined as the absence of talk and she explains it as "distributed silence". Her study discovered that the Japanese use longer pauses as a nonverbalized topic shifting, whereas U.S. participants use a verbalized closing strategy. The 
Japanese use of even-turn-distribution confused U.S. participants because U.S. participants have different turn distribution strategy. Yamada states that U.S. participants attempt to express their opinions through autonomous turn-taking and shorter pauses. Japanese tend to consider these attitudes as selfish and excessively talkative (Yamada, 1989).

Watanabe (1990) compared the classroom discussion behaviors of Japanese groups with those in U.S. groups. She stated that Japanese discussants may consider U.S. discussants disruptive or disorderly. This is because the Japanese discussants expect a U.S. discussant to have turn-taking which lets other people speak out. While the Japanese wait a turn, U.S. subject may unknowingly take a turn. As a consequence, the Japanese end up sitting silently throughout the discussion although they have something to add.

Midooka (1990) states that Japanese communication styles change drastically, depending on how much the communicators know each other or whether or not they are affiliated with the same group. Keeping harmony in interpersonal relations is emphasized when the relationship reaches the level of Najimi no kankei (relationship of acquaintance) (Midooka, 1990). The Japanese approach to the group is to perceive oneself as 
an integral part of the whole, whereas the U.S. approach is to consider the role of the individual in the group (Cathcart \& Cathcart 1988). Japanese find their selfidentity by belonging to a group and they believe society is composed of on-going groups where individual identity is submerged (Cathcart, et al., 1988).

The Japanese desire for group identity can be found in the concept of amae (Doi, 1962). There is no English equivalent of the word amae or amaeru (verb form), but amaeru can be translated as to depend on and presume upon another's love' (Doi, 1962). It is generally used to express a child's attitude toward an adult, especially to his/her parents but it can be applied to any interpersonal relationship between adults, if the relationship contains the same kind of longing for dependency or belonging as a child must have (Doi, 1982). For example, once a person gets hired by a company, he/she becomes an integral part of a corporate group, he/she depends on the company, and he/she finds pleasure and satisfaction within the framework of amae (Cathcart et al., 1988).

As Wagatsuma (1984) states;

Japanese social relations are based upon interdependence among people, and a dependent attitude (amaeru) is not only condoned, but at times encouraged ( $p .372-373$ ).

Amae (interdependence) is often seen in Japanese 
conversation. For example, a Japanese listener gives space, or a silent interval while interacting with others in order to interpret opinions and feelings of the speaker (Naotsuka, 1992). While this speaker is being silent, he/she is expecting and waiting for his/her interactant to understand him/herself. Their communication is based on an interdependent relationship, because the speaker expects the listener to take the initiative of understanding the speaker's intention during a silent moment, and the speaker may not expect the listener to respond verbally immediately.

As Lebra (1987) stated, the Japanese preference for silence is related to his/her awareness of an individual being interdependent and interconnected, inhibiting vocal and self-assertion. The Japanese may become aware of their individualities when they have noticed that they are being interdependent with others who belong to the same group. And in this group, being interdependent (amae) is allowed and the Japanese may use silence in their conversations. In this group, interdependence is predominant over dependence (Okabe, 1984).

Japanese and U.S. Communication patterns and Values

In the literature previously discussed, most of the writers describe Japanese communication as nonverbal oriented (Barnlund, 1989; Okabe, 1983; Tsujimura, 1977; 
Mare, 1990; Midooka, 1990; Minami, 1989; Naotsuka, 1992; Pilgrim, 1986; Ramsey et al., 1983) whereas in the U.S., communication is verbally oriented (Haglund, 1984; Hall et al., 1979; Ishii et al., 1991; Kato et al., 1988; Mare, 1990; Naotsuka, 1992; Okabe, 1983; Ramsey et al., 1983; Yoshikawa, 1982).

This does not mean that the Japanese are always being quiet nor people in the U.S. are always speaking. For example, Philipsen (1990) examined the cultural interpretation of the value of speaking in male role enactment in a particular neighborhood in Chicago, "Teamsterville". He found talk was not valued in the same way as in other places in the U.S., suggesting that "talk is negatively valued in some situations, positively valued in others" (Philipsen, 1990, p. 19). He concludes that "talk is not everywhere valued equally; nor is it anywhere valued equally in all social contexts" (p. 11).

Naotsuka (1992) states that Japanese tend to speak a lot when they are greeting others while they tend to be silent when they are asked for their own opinions. On the other hand, even when speaking English in Japan, people from the U.S. tend to be less verbal when greeting, and more outspoken when they express their own opinions. This may happen because the 'form' of greetings is different between Japanese and American society. For example, 
Japanese people often use the greeting "where are you going" (dochira e ikareruno) when they come across somebody on a street (Ramsey, et al., 1983). To someone from the U.S., this may seem intrusive but this is a way of asking how they are doing rather than as a way to learn their destinations (Ramsey et al., 1983). This form of Japanese greeting keeps a conversation longer and allows people to have more interaction.

The above discussion suggests that the norm of when to speak and when to be silent is somewhat different for Japanese and people from the U.S. As Philipsen (1990) stated "cultures are not only varied but also internally diverse in the emphasis they place on the value of talk" (p. 11). Then the question arises, 'how do people from the U.S. interpret silence?' and 'how do Japanese interpret silence?'

Interpretations of Silence in the U.S. Culture

In observing how U.S. students interpret Japanese communication rules, Nishida (1989) examines their interpretations of Japanese silence in the following two settings; (a) two American males, one American female, and one Japanese female student are having a discussion during the class and the Japanese student remained silent all through the discussion; (b) a Japanese male student visited an American male student's room for the first time 
in the U.S. and the Japanese male student did not answer a question of the American student. Her finding from the first situation where a female Japanese student remained silent during the discussion showed that about 60 percent of American students interpreted Japanese silence negatively, about 20 percent interpreted it neutrally and only 10 percent interpreted it positively (Nishida, 1989). Their negative interpretations were; 'she was passive she was a bit weak in not saying what she was thinking', 'she was totally confused, but she should have asked them what was going on', 'she should have tried to speak up', and 'she has little confidence in herself'. Their neutral interpretations were; 'she is a typical/usual Japanese' and 'she didn't have a chance to talk'. Their positive interpretation was; 'she is polite'.

In the second situation where a Japanese student visited an American student, American interpretations of Japanese silence were different from the first example, which were approximately half negative and half neutral. Their neutral interpretations were; 'there was no fault in the Japanese student's verbal behaviors, and 'the Japanese student is a little bit reserved, but it is understandable because he is in a country which has different culture from his'. Negative interpretations were; 'the Japanese student had better not remain silent that much' and 'the 
Japanese student is too unconfident'. Nishida's finding suggests that most American students interpret a Japanese student's silences either negatively, positively, neutrally, acceptable, not acceptable, adequate, not adequate, preferable, or not preferable.

The interpretations of silence in the negotiation setting among Japanese and U.S. business people have been studied by many scholars (Deutsch, 1983; Fisher, 1980; Graham and Herberger 1983; Hall, 1987; March, 1982, 1988; Hellweg, Samovar, and Skow, 1991; March ,1982; Zimmerman, 1985). Graham and Herberger (1983), among others, argue that U.S. business people don't handle silence well during negotiations. They believe that U.S. business people get into trouble particularly with Japanese negotiators' silence. Hall (1987) states as follows:

The Japanese like to sit back and reflect. They don't feel people have to talk all the time. It doesn't mean they are giving you "the silent treatment" or getting upset or angry; it's simply part of their language of interaction. Periods of silence are very important and should not be broken. Use the time to reflect and enjoy the pauses.

Fisher (1980) states that long pauses are common in Japanese conversation both before responding and in the midale of a developing thought. For someone from the U.S. in such a situation, even fifteen seconds can be a very long time, and they get panicky (Fisher, 1980). 
The U.S. negotiators tend to take Japanese silence during negotiation as a presenting noncommittal attitude (Deutsch, 1983). But "stone-faced silence" means that they are evaluating what their counterparts are saying or that they need more time (Deutsch, 1983). They tend not to answer until they feel they have all the information they need.

Zimmerman (1985) interprets Japanese silence as their willingness to keep a stronger position in a negotiation, and show that it would be unwise for the U.S. negotiator to persuade or cajole them into compromise. Reilly (1990) suggests several interpretations for silence in business settings among Japanese and U.S. business people; (a) the Japanese think silence makes them look better, (b) they think speaking is inappropriate in some situations, or (c) they just don't understand anything that is going on at the meeting.

Hellweg et al. (1991) state that Japanese are more ambiguous with their feelings and ideas than their western counterparts. They utilize silence at the negotiation table and U.S. negotiators perceive it as uncomfortable and indicative of trouble. March (1982) states Japanese negotiating teams have to develop identity, structure and cohesion in their groups. The meeting of these groups can often be painfully slow to Western eyes and it is composed 
of long silences and slowly answered indirect questions when deciaing who will take the first initiative in the negotiation with their counterparts (March, 1982).

As was discussed, silence in a negotiation setting is taken for granted among Japanese, whereas it is interpreted uncomfortably by U.S. negotiators. The U.S. interpretation of the Japanese silence is summarized as: (a) disagreement, (b) noncommittal attitude, (c) getting upset or angry, (d) willingness to keep a stronger position, (e) makes them look better, (f) speaking is inappropriate, (g) don't understand the situation, (h) developing cohesion and identity in a negotiation team, (i) deciding who will take an initiative in a negotiation team.

There are several areas of U.S. culture in which silence is positively interpreted. For example, as discussed earlier, silence is highly valued in Quaker worship (Lippard, 1988), and it is proper to remain silent in particular relationships in certain American speech communities (Philipsen, 1990). According to Barnlund (1989), people from the U.S. once valued silence; 'puritan American nurtured humble forms of speech and made a virtue out of silence' (p. 142).

Interpretation of Silence in Japanese culture

Silence is considered as an important feature of 
Japanese communication (Okabe, 1983; Kindaichi, 1975; Kato, et al., 1991; Klopf, 1991; Midooka, 1993; Miller, 1982; Naotsuka, 1992; Nishida, 1989; Lebra, 1987). Silence is central to Japanese Iife and is used with great sensitivity (Miller, 1982). Silence is a way to avoid losing-face in an argument for the Japanese, and they remain silent when they don't want to compromise (Rowland, 1985). Ramsey et al. (1983) argue that silence may have many situational meanings; time to prepare an opinion, time to consider the appropriate response, time to gather courage when speaking English, a space for waiting for a senior to speak first (Ueda, 1974; Wayne, 1974). Lebra (1987) suggests several possible negative interpretations of silence among Japanese, such as; 'I disagree with you', 'I object', 'I am angry with you', or 'I hate you'. In discussing the functions and interpretation of silence in Japanese culture, Lebra (1987) states;

...silence is... symbolic of logically opposite meanings or emotions. This certainly generates confusion and misunderstanding for a cultural outsider, but for the native as well (p. 351).

Her point is that even though silence is a communicative act, it is too indirect, vague, and confusing, unless interactants know each other enough to communicate without exchanging verbal information of their feelings and thoughts (Lebra, 1987). Lebra's discussion 
of negative interpretation of silence may suggest that silence in Japanese communication is interpreted both positively and negatively. Their interpretation of silence depends on the relationship of interactants. For example, having silence while communicating with somebody a Japanese does not know well, may be interpreted as (a) disagreement, (b) getting upset, and (c) showing hostility. On the other hand, silence of someone a Japanese knows well, may be interpreted as (a) reflecting ideas, (b) pondering, (c) processing ideas, (d) providing a turn, and (e) waiting for someone to speak. Suggested Interpretations of Silence

Johannesen (1974) has paraphrased interpretations of silences studied by several scholars (Greene, 1940; Goodman, 1971; Hugh, 1986; Lebo, 1959; Oliver, 1971; Ong, 1967; Meer100, 1967; Wagner, 1968). By synthesizing both Johannesen's study in 1974, and the literature discussed earlier, the following interpretations of silence among western and eastern cultures are presented.

(1) The silence expresses disagreement.

(2) The silence expresses agreement.

(3) The person feels no sense of urgency about talking.

(4) The person is carefully pondering exactly what to say next.

(5) The person is waiting for somebody else to speak. 
(6) The person thinks that it is inappropriate to talk.

(7) The person is avoiding discussion of a controversial subject and the person is avoiding conflict so as not to hurt the other's feelings.

(8) The person is avoiding a sensitive issue out of fear of losing face.

(9) The person lacks sufficient information to speak on the topic.

(10) The person is uncertain of someone else's meaning.

(11) The person does not understand what is going on.

(12) The person is doubtful or indecisive.

(13) The person is waiting for the other to compromise.

(14) The person is waiting for others to figure out what he/she is thinking or what he/she means.

(15) The person is waiting for his/her turn to speak out.

(16) The person uses silence to enhance his/her own isolation, independence, and sense of selfenlightenment.

(17) The person is in awe, attentive or emotionally overcome.

(18) The person is trying to reach a spiritually unified stage.

(19) The person is daydreaming or preoccupied with other matters.

(20)The person's silence reflects emphatic exchange, the companionship of shared mood or insight.

(21) The person is snooty and impolite.

(22) The person is presenting a noncommittal attitude.

(23) The person is angry and upset.

(24) The silence may simply reflect the person's normal rate of speaking. 


\section{HYPOTHESES}

In the previous section, differences in communication and interpretation of silence of Japanese and people from the U.S. were discussed. Differences in interpreting silence may occur due to the following circumstances; (a) Japanese and U.S. culturally embedded values are different; (b) Japanese and people from the U.S. attribute their communicators' behavior according to their own perceptions, which may be different; (C) Japan and people from the U.S. have different cultural rules which govern their behaviors. Based upon these assumptions, the following hypotheses are presented;

\section{Hypothesis 1 .}

Subjects' concepts of silence will resemble the concept of silence of other subjects with the same nationality more than they will resemble that of other subjects from different nationalities.

People from the U.S. may learn Japanese culture through Japanese cultural practices, leading to an understanding of Japanese cultural rules and values. The concept of acculturation suggests that if people from the U.S. experience Japanese cultural practices, they may develop better skilis in communicating with Japanese. They may also become competent in understanding Japanese values and rules, and behave similarly to Japanese in a 
given situation. Furthermore, people from the U.S. who have studied presented Japanese cultural practices which emphasize the use of silence may begin to display interpretations of silence similar to the Japanese with maintaining their own cultural identity, because as it has been discussed, the silent interval is the central feature for the presented cultural practices. Therefore, the following hypothesis is suggested:

\section{Hypothesis 2.}

The longer the U.S. subjects have studied Japanese cultural practices, the more they may be similar to Japanese in how they interpret silence than to the U.S. subjects who have not studied Japanese cultural practices.

(a) Tea ceremony, (b) calligraphy, (c) flower arrangements, and (d) karate are presented as the Japanese cultural practices which emphasize silence. The following research questions are presented for the thorough analysis and conceptualization of interpretation of silence among Japanese and people from the U.S.

\section{Research Ouestion 1.}

What are the differences in interpretation of silence between Japanese and subjects from the U.S.?

\section{Research Question 2.}

What is the underlying structure of the concept of silence as it is interpreted by Japanese?

\section{Research Question 3 .}

What is the underlying structure of the concept of silence as it is interpreted by the U.S. subjects?

Since there may be differences in interpretation of silence, due to differences in sex, three more research 
questions will be examined in both Japanese and the U.S. cultures.

Research Ouestion 4.

Are there any differences in interpretation of silence between males and females?

Research Question 5 .

Are there any differences in interpretation of silence, due to differences in sex among Japanese?

Research Ouestion 6.

Are there any differences in interpretation of silence, due to differences in sex among the U.S. subjects? 
CHAPTER III

METHODS

\section{Instruments}

Interpretation is guided by how people connect ideas. Thus, interpretation of silence will be guided by how people connect ideas about silence. One of the ways to observe how people connect ideas is to have subjects sort words related to silence and compare the way they arrange the words into groups. Nonmetric multidimensional scaling can be used to estimate the underlying dimensions in the way each group sorts the words, and to compare these dimensions.

Bacon and Richard (1985) studied how parents cognitively structure child behavior and used multidimensional scaling and hierarchical clustering analysis of the measures of psychological distance derived from the sorting cards task. Ritchie, Baker, and Good (1993) studied how people organize their concept of knowledge and use multidimensional scaling and hierarchical clustering analysis. Since the goal of the researcher in this study was to conceptualize interpretation of silence among Japanese and the U.S., (a) 
multidimensional scaling, and (b) hierarchical cluster analysis, were used as the primary methods of analysis.

Subjects for this study were presented a stack of cards which have key words of interpreting silence. They were asked to sort cards into a pile, (one to ten piles), according to their cognition in organizing how the cards go together. The sorted cards were analyzed by using nonmetric multidimensional scaling and hierarchical cluster analysis.

Multidimensional scaling (MDS).

MDS is a series of techniques which analyze and identify key dimensions underlying respondents' evaluation of objects (Joseph, Hare Jr, Anderson, Tatham, \& Block, 1992). In this study, the objects were key words written on cards. The procedure of MDS provides information on the perceived relationship among objects (Dillon \& Goldstein, 1984). MDS uses proximities of many kinds of objects as input and the proximity is a number which indicates how similar or how different two objects are (Kruskal \& Wish, 1976). If words $A$ and $B$ are interpreted by subjects as being most similar compared with all other possible pairs of words, MDS techniques will position words $A$ and $B$ in such a way that the distance between them in multidimensional space is smaller than the distance between any other two pairs of words (Joseph et al., 
1992). Thus, MDS maps the objects in a way that their relative positions in the space reflects the degree of perceived proximity between the objects.

After the words are plotted in the MDS map, the researcher needs to interpret/understand what each dimension means. Since the process of interpreting a MDS map is more of an art than a science, the researcher should not allow personal perception to affect the qualitative interpretation of the dimensions (Joseph et al., 1992). The researcher should be cautious in the interpretation process so as to be as objective as possible. MDS perceptual mapping is most appropriate in (a) identifying unrecognized dimensions affecting behaviors, and (b) obtaining comparative evaluations of objects when the specific concept of comparison is unknown or undefinable (Joseph et al., 1992). The strength of MDS perceptual mapping is its ability to allow a researcher to interpret without the need for defined attributes. The flexibility of perceptual mapping makes it suited to the studies of positioning where the dimensions of evaluation may be too global or emotional/affective to be measured by conventional scales (Joseph et al., 1992).

In this study, subjects' interpretations of silence were analyzed in two ways. First, the card sort results were converted to distance matrices, in which each pair of 
cards is zero units distance if these were sorted into the same group, and one unit distance if they were sorted into a different group. These distance matrices were analyzed by SPSSX procedure INDSCAL and hierarchical cluster analysis.

Second, the interpretation of silence in each of the ten contexts was estimated for each subject by computing a score for each context for each dimension of the INDSCAL solution as follows: words appearing in $\mathrm{X}$ and $\mathrm{Y}$ dimensions on the INDSCAL solution were scored plus one for being placed in $X$, and plus one for being placed in $Y$. On the other hand, words appearing in $-X$ and $-Y$ dimensions were scored minus one for being placed at $-x$ and minus one for being placed in -Y. Every word of each subject was scored based on where each word was plotted on MDS for the total subjects, then compiled and finally standardized by dividing the compiled scores of subjects for the purpose of adjusting the pile size. Standardization was done by dividing the compiled scores of each subject for each context by the number of words in the group associated with that context. The researcher applied this procedure to results from both Japanese and U.S. subjects, and examined whether there was any difference in standardized scores of each context in $\mathrm{Y} /-\mathrm{Y}$ and $\mathrm{X} /-\mathrm{X}$ dimensions. The t-test was used for finding any significant 
differences between Japanese and people from the U.S. in context mean scores.

Hierarchical cluster analysis. Johnson (1967) created hierarchical cluster analysis. This analysis is used to organize the results of the card-sorting obtained from samples (Ritchie et al., 1993). Each succeeding cluster represents a merging of clusters from the preceding level (Bacon et al., 1985).

Each successive level of clustering result when an increasingly larger distance is taken as the criterion for including stimuli in the same cluster (Bacon et al., 1985, p. 198).

Key words for card Sort and Key sentences for describing contexts.

The researcher obtained key words for interpretation and key sentences for describing relationship contexts by synthesizing literature discussed previously (see Appendix $B$ and $C$ ). Context 9: silence when you are with a Japanese friend, needs to be interpreted with special caution, because it is an intercultural situation for the U.S. subjects but a within-culture situation for Japanese.

Subjects' Weights and Average Scores on Dimensions across contexts

Subjects' weights on each dimension of the MDS solution were computed by SPSSX procedure INDSCAL. The subjects' weights describe how strongly each subject relied on a particular dimension in sorting the cards. 
Thus, based on subjects' weights, the degree (the amount) of using each dimension was tested between Japanese and U.S. subjects.

Average scores for each dimension across all ten contexts were examined by ANOVA. Average scores for each dimension over all contexts measure overall reliance on each dimension for interpreting silence. The higher the dimensional score, the more tendency in interpreting silence either positive or active. The lower the dimensional score, the more tendency in interpreting silence either passive or negative. This was tested by ANOVA.

\section{PROCEDURES}

Pilot Study

A pilot study was conducted to test whether the procedure was valid. Subjects were given an explanation of the consent form and their right to refuse participation or quit at any time without any negative consequences. The researcher contacted (a) seventeen Japanese college students, (b) fifteen American college students, all from Portland State University and (C) fourteen Americans who have studied tea ceremony. First, they sorted cards, and next they completed a questionnaire (see Appendix A and D). The researcher chose 38 key words 
(see Appendix B and E) for the cards-sort by synthesizing (a) interpretation of silence among Japanese and people from the U.S. and (b) Johannesen's study in 1974 which discussed earlier in the literature review. English key words were translated into Japanese by the researcher, then back-translation was conducted by a Japanese professor and two graduate students. For the convenience of the subjects, all instructions were given in their native languages. The subjects were presented thirty eight cards which have one key word each, and the following explanation was given;

I am collecting data for my thesis in the Speech Communication department. The project has to do with how people interpret silence. Here is a stack of cards, each card has a word on it. Please sort these cards into piles that have something in common with each other, use one to ten piles. Each word may be used in one and only one category.

The subjects were then asked to sort into piles individually. The American subjects sorted English cards and the Japanese subjects sorted Japanese cards. After the cards had been sorted subjects were asked to identify one group of words that go best with each of the ten contexts (see Appendix $\mathrm{C}$ and $\mathrm{F}$ ). The ten situation and relationship contexts are suggested from the situations where silence occurs, discussed earlier in the literature review. The subjects were asked to add to the list any 
additional words related to interpretation of silence that . they think should be included. Subjects were asked to omit any words from the list that they thought should not be included.

\section{Main Study}

Four hundred seventy eight subjects responded all together. Two hundred seventy eight Japanese college students (128 males and 150 females) were recruited from Universities in Japan. One hundred ninety four Americans (91 males and 103 females) were recruited from Portland State University and Japanese cultural groups.

From the pilot study, the researcher reduced the list of key words that people associate with the ideas of silence into thirty five words. The key words represent descriptions of the attributes of silence. The researcher recruited subjects from Universities in Japan, Portland State University, and Japanese cultural groups in the Portland area, and had them sort the cards. After subjects filled in the demographic information, the following explanation was given;

I am collecting data for my thesis in the Speech Communication department. The project has to do with how people interpret silence. Here is a stack of cards, each card has a word on it. Please sort these cards into piles that have something in common with each other, use as many piles as you need. Each word may be used in one and only one category. 
Then, the subjects were presented with the stack of cards and asked to sort into piles. The U.S. subjects sorted English cards and the Japanese subjects sorted Japanese cards. After the cards have been sorted, subjects were asked to identify one group of words that go best with each of the ten contexts. For the convenience of the subjects, all instructions were given in their native languages. 
CHAPTER IV

This chapter presents the findings of the data analysis. The chapter begins with a discussion of the subjects' characteristics, and presents the results of the data analysis. Alpha level for all statistical analysis tests. was set at .05 in this study.

\section{RESULTS}

\section{SUBJECTS' CHARACTERISTICS}

Four hundred seventy eight subjects responded all together (see Table I). Two hundred seventy eight Japanese college students (128 males and 150 females) were recruited from Chiba University and Sano Women's University in Japan. One hundred ninety four Americans (91 males and 103 females) were recruited from Portland State University and the following Japanese cultural groups: Urasenke Portland Wakai Dokokai, Sogetsu School of Ikebana, Ampersand Studio, Two River Aikikai, American State Karate, Professional Martial Arts Association, and John Daniel Martial Arts. For valid comparison among subjects, subjects who didn't use all thirty five words for a card sort were discarded. This procedure reduced the total subjects to 384 (see Table II). There were 244 
Japanese subjects (113 males and 131 females), and 139 American subjects ( 62 males and 77 females). Chi-square on nationalities and sex showed that there was no significance difference in the proportion of men and women in the Japanese and U.S. sub-samples.

The researcher compared the nationalities and sex against length of time of experiencing Japanese cultural arts. The length of time of experiences were categorized (a) no experience, (b) less than one year of experience, and (b) more than one year of experience. (see Table III through Table VI).

TABLE 1

SUBJECTS GATHERED

\begin{tabular}{|l|r|r|r|}
\hline & male & female & Total \\
\hline Japanese & 128 & 150 & 278 \\
\hline The U.S. & 91 & 103 & 194 \\
\hline Total & 219 & 253 & 472 \\
\hline
\end{tabular}

TABLE $\|$

SUBJECTS USED FOR THE STUDY

\begin{tabular}{|l|r|r|r|}
\hline & male & female & total \\
\hline Japanese & 113 & 131 & 244 \\
\hline The U.S. & 62 & 77 & 139 \\
\hline Total & 175 & 208 & 383 \\
\hline
\end{tabular}


TABLE III

\section{SUBJECTS EXPERIENCED TEA CEREMONY}

\begin{tabular}{|l|r|r|r|r|r|r|}
\hline & \multicolumn{3}{|l|}{ less than 1 year } & \multicolumn{3}{l|}{ more than 1 year } \\
\cline { 2 - 7 } & male & female & Total & male & female & Total \\
\hline Japanese & 40 & 65 & 105 & 0 & 12 & 12 \\
\hline The U.S. & 18 & 19 & 37 & 2 & 3 & 5 \\
\hline Total & 58 & 84 & 142 & 2 & 15 & 17 \\
\hline
\end{tabular}

TABLE IV

SUBJECTS EXPERIENCED CALLIGRAPHY

\begin{tabular}{|l|l|l|l|l|l|r|}
\hline & \multicolumn{3}{|l|}{ less than 1 yrar } & \multicolumn{3}{l|}{ more than 1 year } \\
\cline { 2 - 7 } & male & fermale & Total & male & female & Total \\
\hline Japanese & 21 & 20 & 41 & 33 & 75 & 108 \\
\hline The U.S. & 15 & 31 & 46 & 1 & 5 & 6 \\
\hline Total & 36 & 51 & 87 & 34 & 80 & 114 \\
\hline
\end{tabular}

TABLE $V$

SUBJECTS EXPERIENCED FLOWER ARRANGEMENT

\begin{tabular}{|l|l|l|l|l|l|r|}
\hline & \multicolumn{3}{|l|}{ less than one year } & \multicolumn{3}{l|}{ more than 1 year } \\
\cline { 2 - 8 } & male & female & Total & male & female & Total \\
\hline Japanese & 38 & 65 & 103 & 0 & 8 & 8 \\
\hline The U.S. & 14 & 21 & 35 & 1 & 3 & 4 \\
\hline Total & 52 & 86 & 138 & 1 & 11 & 12 \\
\hline
\end{tabular}

TABLE VI

SUBJECTS EXPERIENCED KARATE

\begin{tabular}{|l|r|r|r|r|r|r|r|}
\hline & \multicolumn{4}{|l|}{ less than one year } & \multicolumn{3}{l|}{ more than 1 year } \\
\cline { 2 - 8 } & male & female & Total & male & female & Total \\
\hline Japanese & 40 & 67 & 107 & 4 & 1 & 5 \\
\hline The U.S. & 22 & 25 & 47 & 18 & 8 & 26 \\
\hline Total & 62 & 92 & 154 & 22 & 9 & 31 \\
\hline
\end{tabular}


Among tea ceremony subjects, 142 subjects experienced less than one year and 17 subjects experienced more than one year (see Table III). Among Calligraphy subjects, 87 subjects responded with experience of less than one year and 114 subjects experienced more than one year (see Table IV). Among Flower arrangement subjects, 138 subjects experienced less than one year and 12 subjects experienced more than one year (see Table V). Among karate subjects, 154 subjects responded with experience of less than one year and 31 subjects experienced more than one year (see Table VI).

Because of the small number of Japanese and U.S. subjects experiencing Japanese arts more than one year, the researcher was unable to examine how practicing Japanese arts influence the U.S. subjects on their interpretation of silence.

The average age of the U.S. subjects was 27.23 compared to 20.17 for Japanese subjects $(\underline{t}=-10.56$, $\mathrm{p} \leq .001)$. The U.S. subjects sorted the words into an average of 7.53 groups, compared to 8.85 for Japanese ( $\underline{t}$ $=7.51, \mathrm{p} \leq .01)$. Therefore, age and numbers of groups were entered as covariates in all analyses.

The length of education by nationalities is shown in Table VII. Major by nationalities is shown in Table VIII. 
TABLE VII

EDUCATION BY NATIONALITIES

\begin{tabular}{|l|r|r|r|}
\hline & Japanese & The U.S. & Total \\
\hline no college & 0 & 6 & 6 \\
\hline one year & 77 & 44 & 121 \\
\hline two years & 117 & 20 & 137 \\
\hline three years & 29 & 15 & 44 \\
\hline four years & 10 & 18 & 28 \\
\hline five years & 4 & 13 & 17 \\
\hline six years & 0 & 13 & 13 \\
\hline seven years & 0 & 1 & 1 \\
\hline eight years & 0 & 2 & 2 \\
\hline nine years & 1 & 0 & 1 \\
\hline ten years & 0 & 1 & 1 \\
\hline eleven years & 0 & 1 & 1 \\
\hline twelve years & 0 & 1 & 1 \\
\hline Total & 238 & 135 & 373 \\
\hline
\end{tabular}

TABLE VIII

MAJOR BY NATIONALITIES

\begin{tabular}{|l|r|r|r|}
\hline Mojor & Japanese & The U.S. & Total \\
\hline Business & 212 & 15 & 227 \\
\hline Fine Arts & 0 & 12 & 12 \\
\hline Mathematics & 1 & 40 & 41 \\
\hline Social Science & 20 & 17 & 37 \\
\hline Engineering & 0 & 7 & 7 \\
\hline Humanities & 5 & 8 & 13 \\
\hline Professional & 2 & 14 & 16 \\
\hline Others & 2 & 13 & 15 \\
\hline Total & 242 & 126 & 368 \\
\hline
\end{tabular}

Multi Dimensional Scaling (MDS)

The researcher mapped words into two dimensions and three dimensions, using ALSCAL in SPSSX. The two dimensional solution produced two interpretable 
dimensions, stress $=.536$. The three dimensional solution reduced stress to .452, but did not produce an interpretable third dimension. Consequently, the two dimensional solution was used.

By examining what kinds of words were clustered together, the following labels were given to the $Y /-Y$ and $\mathrm{X} / \mathrm{X}$ axes: (a) positive vs negative dimension, and (b) passive vs active dimension. These labels were applied to a data with all subjects, a data of Japanese subjects only, and a data of the U.S. subjects only.

\section{Interpretation of Two Dimension Scaling: A11}

\section{Subjects.}

Words in negative and active dimensions are interpreted as a conflict clustering (see figure 3). The reasons are inappropriate, disagree, and conflict are grouped at a center of the cluster in the dimension. Words in the negative and passive dimension are interpreted as withdrawal clustering, because passive, non-committal attitude, and reserved grouped together in the the passive/negative dimension.

Words in positive and active dimensions may be interpreted as private/inner clustering. The reason is spiritual, insight, and self-enlightenment grouped together in a center of the positive/active dimension, and 


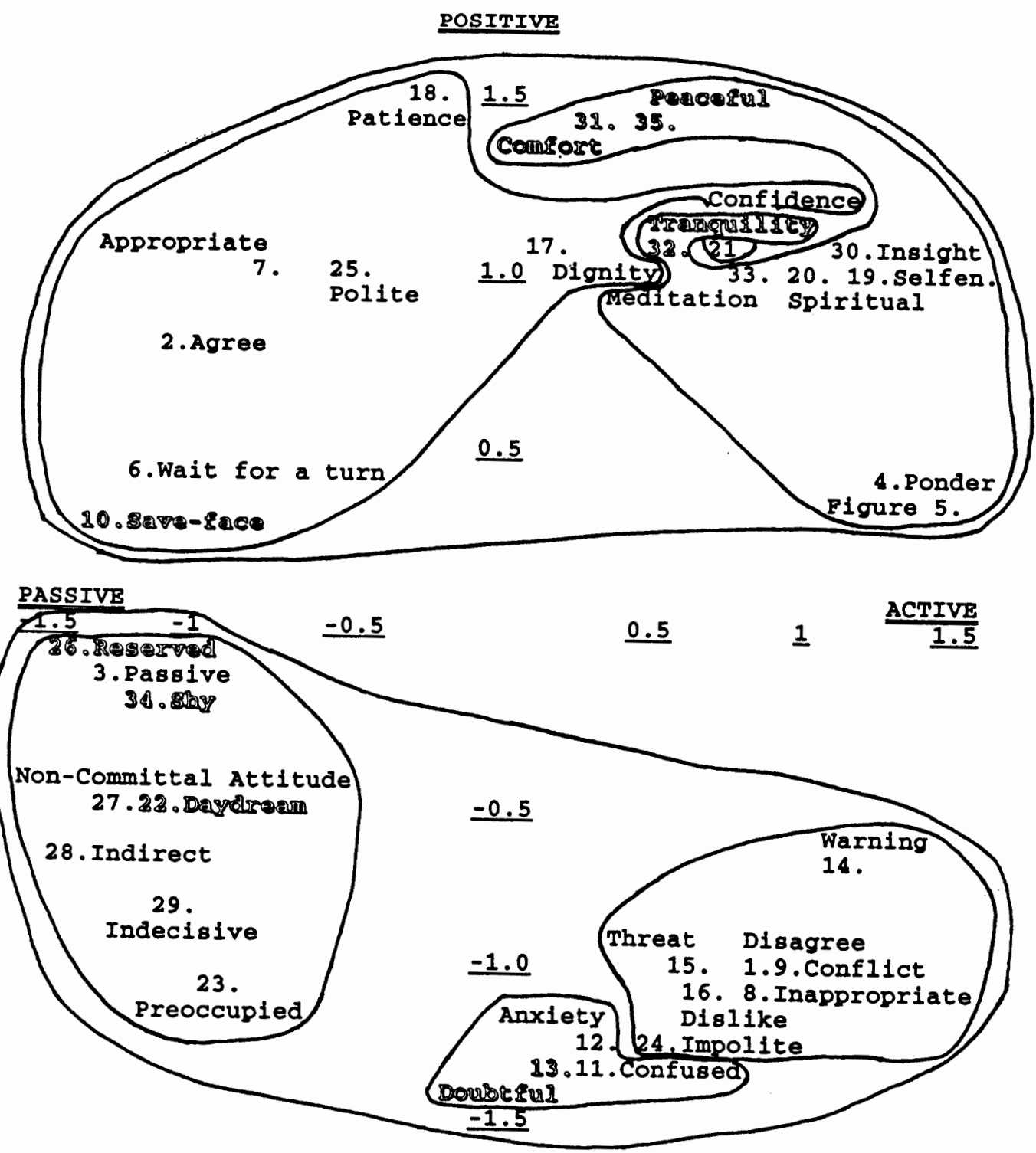

\section{NEGATIVE}

Figure 3. Multidimensional scaling for "all subjects". This figure shows the cognitive space mapping for the interpretation of silence of both Japanese and U.S. subjects. 
these may be related to private inner self. Positive and passive dimensions may be interpreted as public/outer clustering, because wait for a turn, polite and agree clustered together in the positive/passive dimension, and these may signify the concept in how to communicate with others at a public level.

\section{Hypothesis 1.}

Subjects' concepts of silence will resemble the concept of silence of other subjects with the same nationality more than they will resemble that of other subjects from different nationalities.

Subjects' Weights

Mean subjects weights on the INDSCAL solution were examined. As Table IX shows, the mean of subjects' weights for the U.S. subjects on dimension 1 (positive/negative) were .25 compared to .20 for Japanese, $E(1,377)=7.36$, $\mathrm{p} \leq .01$. In dimension 2, the mean of subjects' weights for the U.S. subjects were .23 compared to .19 for Japanese, $\underline{E}(1,377)=5.08, p \leq .01$ (see Table IX). The U.S. subjects used dimension 1 (positive/negative) and dimension 2 (active/passive) more than Japanese.

There is no significant difference between males and females, overall. However, the interaction between sex and nationality is significant, in dimension $1, \underline{E}(1,377)$ $=11.14, p \leq .001$, and in dimension $2, E(1,377)=10.66$, p<.001. In dimension 1, the mean of subjects' weights for U.S. females were .27 compared to .19 for Japanese 
females, .21 for Japanese males and .23 for the U.S.

\section{TABLE IX}

\section{SUBJECTS' WEIGHTS}

Dimension 1: Positive/Negative

\begin{tabular}{|l|r|r|r|}
\hline & Japanese & The U.S. & \multicolumn{1}{l|}{ Total } \\
\hline Male & $\mathbf{0 . 2 1}$ & $\mathbf{0 . 2 3}$ & $\mathbf{0 . 2 1}$ \\
\hline Number of Subj. & 113.00 & 62.00 & 175.00 \\
\hline Female & 0.19 & $\mathbf{0 . 2 7}$ & $\mathbf{0 . 2 2}$ \\
\hline Number of Subj. & 131.00 & 77.00 & 208.00 \\
\hline Total & 0.20 & 0.25 & 0.22 \\
\hline Total Subj. & 244.00 & 139.00 & 383.00 \\
\hline
\end{tabular}

Dimension 2: Active/Passive

\begin{tabular}{|l|r|r|r|}
\hline & Japanese & The U.S. & Total \\
\hline Male & 0.20 & 0.21 & 0.20 \\
\hline Number of Subj. & 113.00 & 62.00 & 175.00 \\
\hline Female & 0.18 & 0.24 & 0.20 \\
\hline Number of Subj. & 131.00 & 77.00 & 208.00 \\
\hline Total & 0.19 & 0.23 & 0.20 \\
\hline Total Subj. & 244.00 & 139.00 & 385.00 \\
\hline
\end{tabular}

males, $\underline{E}(1.377)=7.36, \mathrm{p} \leq .01$. In dimension 2 , the mean of subjects' weights for U.S. females were .24 compared to .18 for Japanese females, .20 for Japanese males, and .21 for the U.S. males. The U.S. females use dimension 1 (positive/negative) and dimension 2 (active/passive) more than the Japanese females, Japanese males or the U.S. males. In addition, Japanese females use dimension 1 (positive/negative) and dimension 2 (active/passive) less 
than Japanese males, less than the U.S. males and less than the U.S. females. Japanese males and U.S. males use dimension 1 (positive/negative) and dimension 2 (active/passive) almost to the same degree.

The U.S. subjects use both dimensions more than Japanese. For both dimensions, there is no significant difference between males and females, however, there is the interaction between sex and nationality. The U.S. females use both dimensions more than Japanese females, Japanese males or the U.S. males. Japanese females use both dimensions less than the U.S. females, less than the U.S. males or less than Japanese males.

Average overall Interpretation of Silence

Mean scores of differences in using each dimension for interpreting silence in each context were examined by Analysis of Variance (ANOVA) in the positive/negative and active/passive dimensions. Two-way ANOVA was used. Higher scores on dimension 1 mean silence is interpreted as more positive; higher scores on dimension 2 means silence is interpreted as more active. Examining average scores for using each dimension across contexts leads to an average overall interpretation of silence.

As Table $\mathrm{X}$ shows, average scores for the U.S. subjects on dimension 1 (positive/negative) were .33 compared to .02 for Japanese, $\underline{F}(1,366)=32.35, \mathrm{p} \leq .001$. 
The U.S. subjects interpret silence as more positive overall (across all contexts) than do Japanese. There is no significant difference between males and females, overall, and there is no interaction between nationality and sex.

As the Table $\mathrm{X}$ shows, the average scores for the U.S.

TABLE X

AVERAGE OVERALL INTERPRETATION OF SILENCE

Dimension 1: Positive/Negative

\begin{tabular}{|l|r|r|r|}
\hline & Japanese & The U.S. & \multicolumn{1}{l|}{ Total } \\
\hline Male & 0.01 & 0.28 & 0.10 \\
\hline Number of Subj. & 112.00 & 58.00 & 170.00 \\
\hline Female & 0.02 & 0.37 & 0.15 \\
\hline Number of Subj. & 129.00 & 73.00 & 202.00 \\
\hline Total & 0.02 & 0.33 & 0.13 \\
\hline Total Subj. & 241.00 & 131.00 & 372.00 \\
\hline
\end{tabular}

Dimension 2: Active/Passive

\begin{tabular}{|l|r|r|r|}
\hline & Japanese & The U.S. & \multicolumn{1}{l|}{ Total } \\
\hline Male & 0.30 & 0.18 & 0.26 \\
\hline Number of Subj. & 112.00 & 58.00 & 170.00 \\
\hline Female & 0.29 & 0.16 & 0.24 \\
\hline Number of Subj. & 129.00 & 73.00 & 202.00 \\
\hline Total & 0.29 & 0.17 & 0.25 \\
\hline Total Subj. & 241.00 & 131.00 & 372.00 \\
\hline
\end{tabular}

subjects on dimension 2 (passive/active) were .17 compared to .29 for Japanese, $F(1,366)=11.74, p \leq .001$. There is no significant difference between males and females on dimension 2 (active/passive). Also, there is no 
interaction between nationality and sex.

The significant difference in how silence is interpreted overall across contexts is found on the positive/negative and passive/active dimensions between Japanese and U.S. subjects. The U.S. subjects interpret silence as more positive than Japanese. Japanese interpret silence as more active than U.S. subjects. Sex and the interaction between nationality and sex is insignificant on both dimensions.

Interpretation of Silence in Interaction contexts

The overall comparison between Japanese and U.S. subjects can be better understood by examining how members of each nationality interpret silence in each of the separate contexts. Based upon how subjects sorted cards into contexts, mean dimension scores associated with each context were examined by t-test (see Table XI).

TABLE XI

MEAN DIMENSION SCORES ASSOCIATED WITH EACH CONTEX

Context 1: discussing holiday with your intimate friend

\begin{tabular}{|l|r|r|r|l|}
\hline & Japanese & The U.S. & F-value & Sig. F \\
\hline Number of Subj. & 234.00 & 117.00 & & \\
\hline Positive/Negative & -0.05 & 0.45 & 16.45 & P<.001 \\
\hline Active/Passive & 0.15 & 0.14 & 0.03 & n.s \\
\hline
\end{tabular}

Context 2: negotiating with teacher to change grade

\begin{tabular}{|l|r|r|r|l|}
\hline & Japanese & The U.S. & F-value & Sig. F \\
\hline Number of Subj. & 234.00 & 117.00 & & \\
\hline Positive/Negative & -0.19 & 0.22 & 10.63 & $\mathrm{p}<.001$ \\
\hline Active/Passive & $\mathbf{0 . 4 2}$ & -0.08 & 16.31 & $\mathrm{p}<.01$ \\
\hline
\end{tabular}


Context 3: silence of your partner in front of you

\begin{tabular}{|l|r|r|r|l|}
\hline & Japanese & The U.S. & F-value & Sig. F \\
\hline Number of Subj. & 234.00 & 117.00 & & \\
\hline Positive/Negative & -0.27 & 0.19 & 8.13 & P $<.01$ \\
\hline Active/Passive & 0.16 & 0.07 & 3.62 & n.s \\
\hline
\end{tabular}

Context 4: silence of your boss in front of you

\begin{tabular}{|l|r|r|r|l|}
\hline & Japanese & The U.S. & F-value & Sig. F \\
\hline Number of Subj. & 234.00 & 117.00 & & \\
\hline Positive/Negative & -0.11 & -0.03 & 0.43 & n.s \\
\hline Active/Passive & 0.38 & 0.09 & 8.45 & p<.01 \\
\hline
\end{tabular}

Context 5: silence of your father or mather in front of you

\begin{tabular}{|l|r|r|r|l|}
\hline & \multicolumn{1}{|c|}{ Japanese } & The U.S. & F-value & Sig. F \\
\hline Number of Subj. & 234.00 & 117.00 & & \\
\hline Positive/Negative & 0.02 & 0.22 & 3.18 & n.s \\
\hline Active/Passive & 0.40 & 0.13 & 3.20 & n.s \\
\hline
\end{tabular}

Context 6: silence of your teacher during class

\begin{tabular}{|l|r|r|r|l|}
\hline & Japanese & The U.S. & F-value & Sig. F \\
\hline Number of Subj. & 227.00 & 60.00 & & \\
\hline Positive/Negative & -0.04 & 0.49 & 7.59 & $\mathrm{p}<.01$ \\
\hline Active/Passive & 0.34 & -0.03 & 14.48 & $\mathrm{p}<.001$ \\
\hline
\end{tabular}

Context 7: silence of your same sex intimate friend

\begin{tabular}{|l|r|r|r|l|}
\hline & Japanese & The U.S. & F-value & Sig. F \\
\hline Number of Subj. & 227.00 & 60.00 & & \\
\hline Positive/Negative & 0.00 & 0.53 & 9.77 & $\mathrm{p}<.01$ \\
\hline Active/Passive & $\mathbf{0 . 1 1}$ & $\mathbf{0 . 3 4}$ & $\mathbf{7 . 3 1}$ & $\mathrm{p}<.01$ \\
\hline
\end{tabular}

Context 8: silence when you are alone

\begin{tabular}{|l|r|r|r|l|}
\hline & Japanese & The U.S. & F-value & Sig. F \\
\hline Number of Subj. & 227.00 & 60.00 & & \\
\hline Positive/Negative & 0.33 & 0.75 & 2.84 & n.s \\
\hline Active/Passive & 0.28 & 0.54 & 0.42 & n.s \\
\hline
\end{tabular}

Context 9: silence of your Japanese friend

\begin{tabular}{|l|r|r|r|l|}
\hline & Japanese & The U.S. & F-value & Sig. F \\
\hline Number of Subj. & 227.00 & 60.00 & & \\
\hline Positive/Negative & -0.34 & 0.52 & 25.74 & $\mathrm{p}<.001$ \\
\hline Active/Passive & 0.27 & -0.01 & 2.86 & n.s \\
\hline
\end{tabular}


Context 10: silence when you are practicing JPN arts

\begin{tabular}{|l|r|r|r|l|}
\hline & \multicolumn{1}{|c|}{ Japanese } & The U.S. & F-value & Sig. F \\
\hline Number of Subj. & 227.00 & 60.00 & & \\
\hline Positive/Negative & 0.73 & 0.66 & 0.53 & n.s \\
\hline Active/Passive & 0.37 & 0.46 & 0.77 & n.s \\
\hline
\end{tabular}

T-test compares difference in mean scores. T-test value of .05 or smaller shows two variables as having a significant difference. Twelve out of 18 comparisons showed significant differences between Japanese and U.S. subjects.

\section{Overall pattern}

In figure 4, the interpretation of silence by members of each nationality is plotted on the positive-negative and active-passive dimensions, for ease of comparison. The U.S. subjects interpret silence significantly more positively than Japanese in seven contexts: silence when you are alone, silence while deciding what to do with your intimate friend, silence of your same sex intimate friend, silence of your teacher during the class, parents' silence in front of you, partner's silence in front of you, and silence of your teacher while negotiating the changing of your grade. Japanese do not interpret silence more positively than the U.S. subjects in any contexts.

On average, silence is interpreted as much more 
positive by the U.S. subjects (mean $=.33$ ) than by Japanese $($ mean $=.02)$. On average, silence is interpreted as much more active by Japanese (mean $=.29$ ) than by the U.S. subjects $($ mean $=.17)$. Japanese interpreted silence significantly more active than the U.S. subjects in four of the contexts: silence of your teacher while negotiating the changing of your grade, teacher's silence in front of you, boss' silence in front of you, and parents' silence in front of you. The U.S. subjects interpret silence as significantly more active than do Japanese in one of the contexts: silence when you are alone.

As figure 4 shows, both the U.S. and Japanese plotted contexts either on positive/active quadrant (private/outer clustering) or negative/active (conflict clustering) quadrant. The U.S. subjects mostly plot contexts on positive/active quadrant, and this may suggest that people from the U.S. tend to relate silence in particular contexts with private/outer activities. On the other hand, Japanese mostly plot contexts on negative/active quadrant. This may suggest that Japanese tend to interpret silence in particular contexts as negative/active silence.

\section{Hypothesis 2.}

The longer the U.S. subjects have studied Japanese cultural practices, the more they may be similar to Japanese in how they interpret silence than to the U.S. subjects who have not studied Japanese cultural practices. 


\section{POSITIVE}

A, J arts

\section{alone, $\mathbb{A}$}

0.6

A, JPN friend

\$, hollday friend

0.4
J arts, J
J,alone
A, teacher

$0.2 \quad$, pare
A, partner
, grade
PASSIVE
$-0.4 \quad-0.2$
$\underset{0}{\text { friend, J }} \quad 0.2^{\text {parents, }} \quad 0.4 \quad \frac{\text { ACTIVE }}{0.6}$
boss, \& J Joliday $\underline{\text { J }}$, teacher
J, boss
$-0.2$
J, grade
JPN $\begin{aligned} & \text { J,partner } \\ & \text { Eriend, } \underline{J}\end{aligned}$
$-0.4$
$-0.6$
NEGATIVE

Figure 4. Contexts Map. This figure shows how Japanese and the U.S. subjects placed contexts on each dimension. A stands for the U.S. contexts map and $\mathbf{I}$ stands for Japanese context map. 
Mean of Subjects' Weights: Nationalities by Japanese Arts Mean scores of differences in sorting cards were examined by Analysis of Variance (ANOVA) in the positive/negative and active/passive dimensions. Two-way ANOVA was used. Significant differences were found in only two out of 18 contexts. Those differences may have been caused by a statistic artifact. Also, since very few subjects of either nationality had experienced Japanese arts, it was not possible to test this hypothesis adequately. Consequently, no conclusion may be drawn.

Research Ouestion 1.

What are the differences in interpretation of silence between Japanese and U.S. subjects?

Research Question 2 .

What is the underlying structure of the concept of silence as it is interpreted by Japanese?

Research Question 3 . What is the underlying structure of the concept of silence as it is interpreted by U.S. subjects?

Multi Dimensional Scaling (MDS)

Because of observed differences in subjects' weights between the U.S. and Japanese subjects, separate INDSCAL solutions were computed for each nationality.

Comparison of Japanese VS U.S. subjects in MDS Mapping.

Although the overall solutions were quite similar between Japanese and U.S. subjects, several words appear in different quadrants in the MDS maps computed for the 
two nationalities (see figure 5 and 6 ).

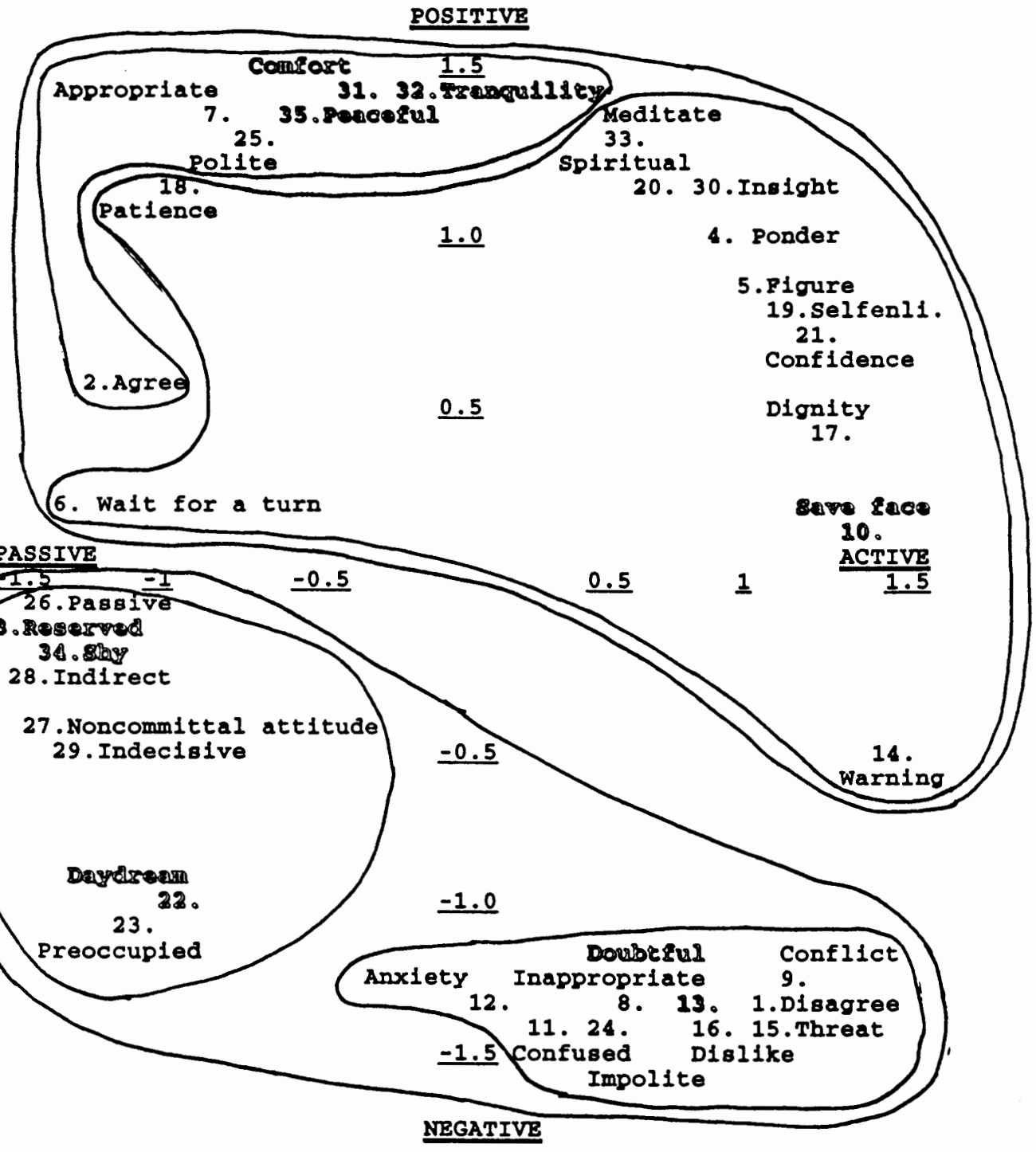

Figure 5. Multidimensional Scaling for Japanese subjects. 

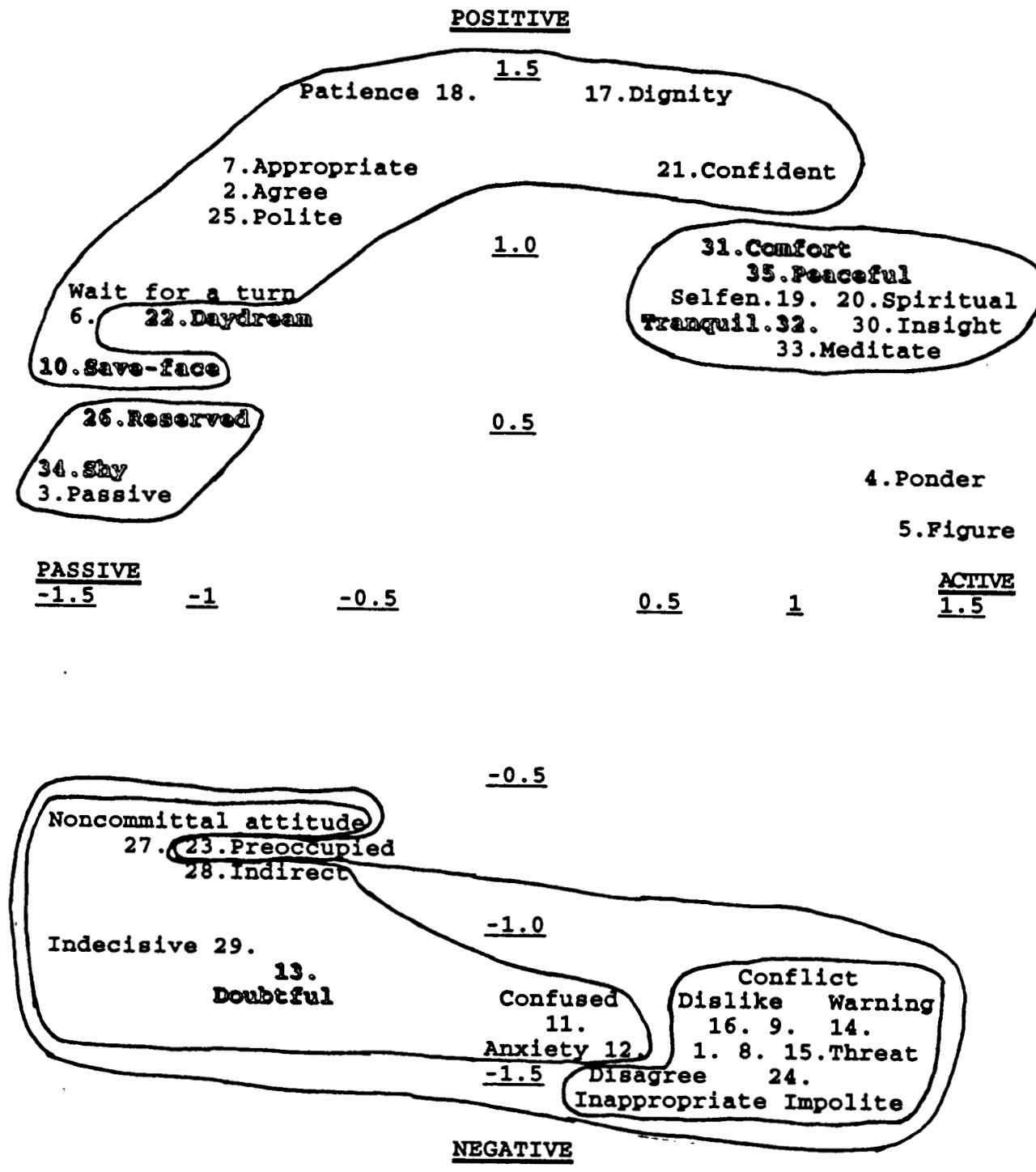

Fiqure 6. Multidimensional Scaling for the U.S. subjects. 
Comfort, peaceful, and tranquility were placed in the positive/active dimension (private/outer clustering) by the U.S. subjects, and were placed in the positive/passive dimension (public/inner clustering) by Japanese. Daydream was located in the positive/passive dimension (public/inner clustering) by the U.S. subjects and was located in negative/passive dimension (withdrawal clustering) by Japanese. Doubtful was placed in the negative/passive dimension (withdrawal clustering) by the U.S. subjects and was placed in the negative/active dimension (conflict clustering) by Japanese. Save-face was placed in the positive/passive dimension (public/inner clustering) by the U.S. subjects and was placed in the positive/active dimension (private/outer clustering) by Japanese.

Research Question 4. Are there any differences in interpretation of silence between males and females?

Research Ouestion 5. Are there any differences in interpretation of silence, due to differences in sex among Japanese?

Research Question 6.

Are there any differences in interpretation of silence, due to differences in sex among U.S. subjects?

Differences due to sex were examined by studying subjects' weights and average scores for using dimensions across contexts. There is no significant difference between males and females overall (see Table IX and 
Table X) .

However, the interaction between sex and nationality is significant, $\underline{E}(1,377)=11.14, p \leq .001$, in subjects' weights on the positive/negative dimension (see Table IX). The mean of subjects' weights for the U.S. females were .27 compared to .19 for Japanese females, .21 for Japanese males and .23 for the U.S. males, $\underline{E}(1.377)=7.36, p \leq .01$. In the active/passive dimension on subjects' weights, the interaction between sex and nationality is also significant, $\underline{E}(1,377)=10.66, \underline{p}<.001$. The mean of subjects' weights for the U.S. females were .24 compared to .18 for Japanese females, .20 for Japanese males, and .21 for the U.S. males.

In examining subjects' weights, although there is no significant difference between males and females, the interaction between sex and nationality is significant. The U.S. females use both dimensions more than Japanese females, Japanese males or the U.S. males. Japanese females use both dimensions less than the U.S. females, less than the U.S. males or less than Japanese males.

\section{SUMMARY OF RESULTS}

Differences in interpretation of silence between Japanese and U.S. subjects were examined by Multidimensional scaling (MDS), hierarchical analysis, 
Analysis of Variance (ANOVA), and t-test. Although hypothesis 1 is only weakly supported by differences in subjects' weights on the MDS solution, it is strongly supported by t-test which showed significant differences in almost all of the ten contexts.

The result from subjects' weights revealed that the degree of using the positive/negative dimension and the passive/active dimensions are similar between Japanese males and females, and similar between the U.S. males and females. The differences were found between Japanese females and U.S. females. The U.S. females use the positive/negative and passive/active dimensions more than Japanese females. The difference between Japanese males and U.S. males were slight.

Mean scores of difference in using each dimension for interpreting silence in each context showed that there are significant differences in the positive/negative and passive/active dimensions between Japanese and U.S. subjects. Overall, examining the average interpretation scores across all contexts, Japanese are more likely than the U.S. subjects to interpret silence as active (mean = .29 for Japanese compared to .17 for U.S. subjects, F(1, $366)=11.74, \mathrm{p}<.001)$. The U.S. subjects are more likely than Japanese to interpret silence as positive (mean $=.33$ for the U.S. subjects compared to .02 for Japanese F(1, 
$366)=32.35, p<.001)$. Japanese are more likely to interpret silence as active and less likely to interpret silence as positive; the U.S. subjects are more likely to interpret silence as positive and less likely to interpret silence as active.

Looking at the interpretation of silence in particular contexts (see figure 7 to 16), Japanese

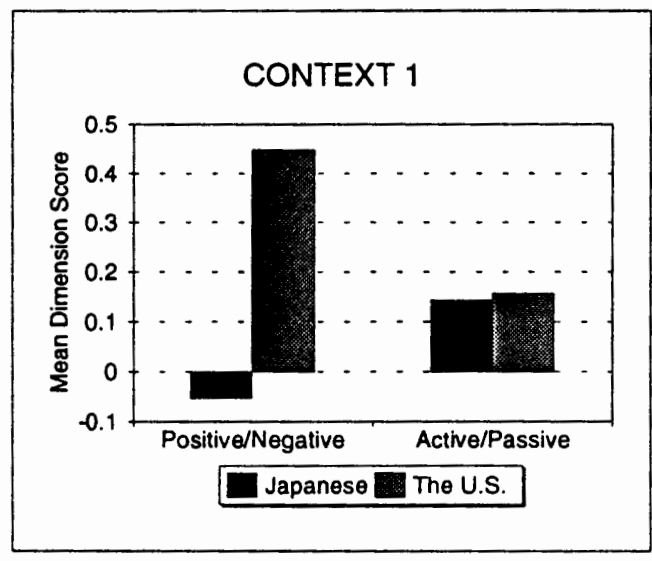

Figure 7. Discussing holiday with your intimate friend.

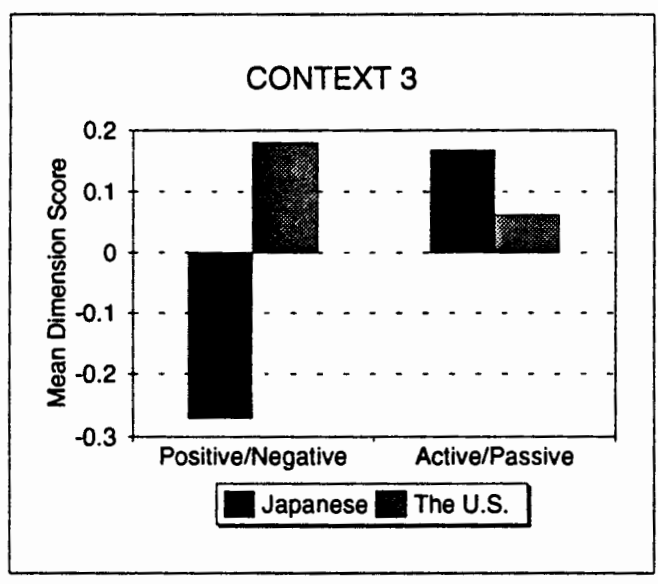

Figure 9. Silence of your partner in front of you.

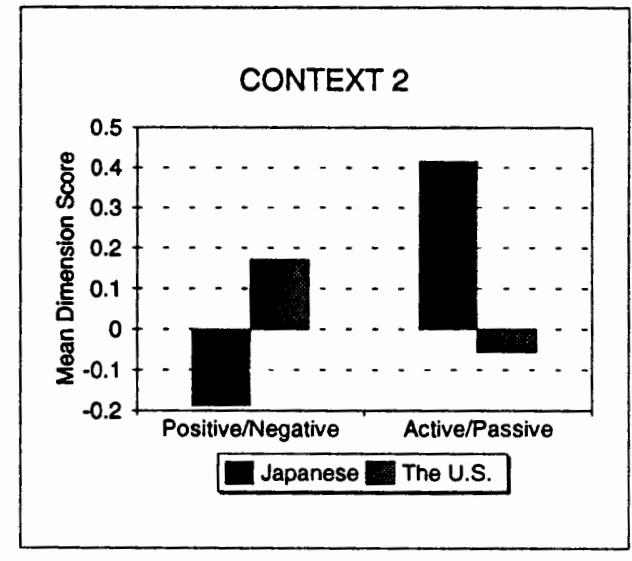

Figure 8. Negotiating with teacher to change a grade.

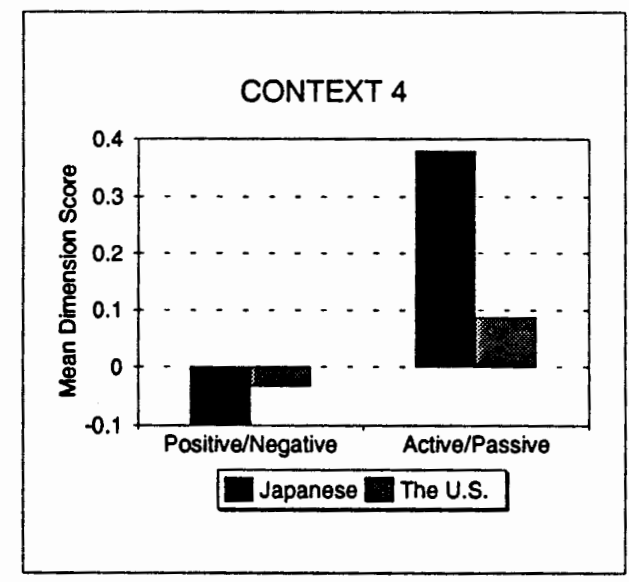

Figure 10. Silence of your boss in front of you. 


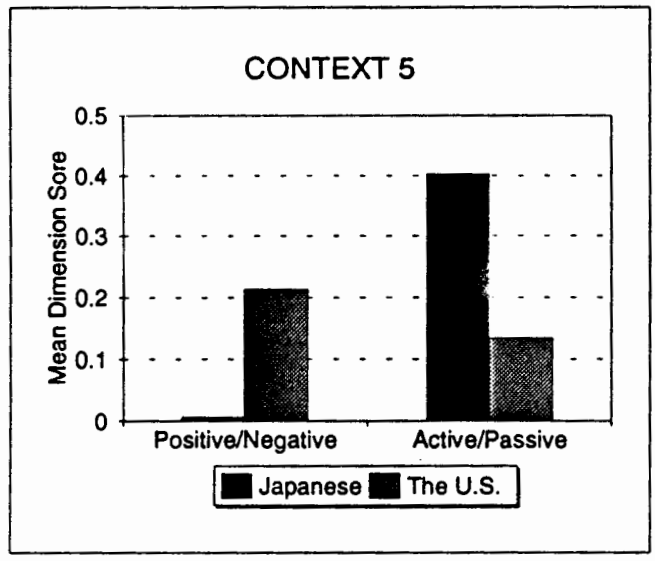

Figure. 11 Silence of your parents in front of you.

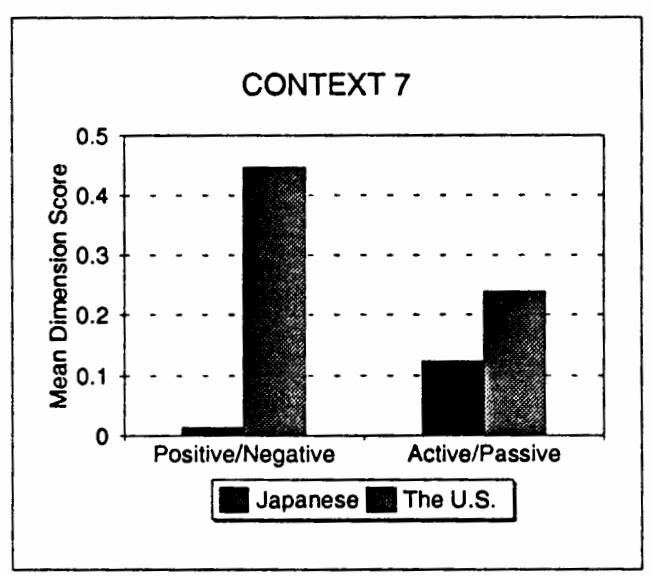

Figure 13. Silence of your same sex intimate friend.

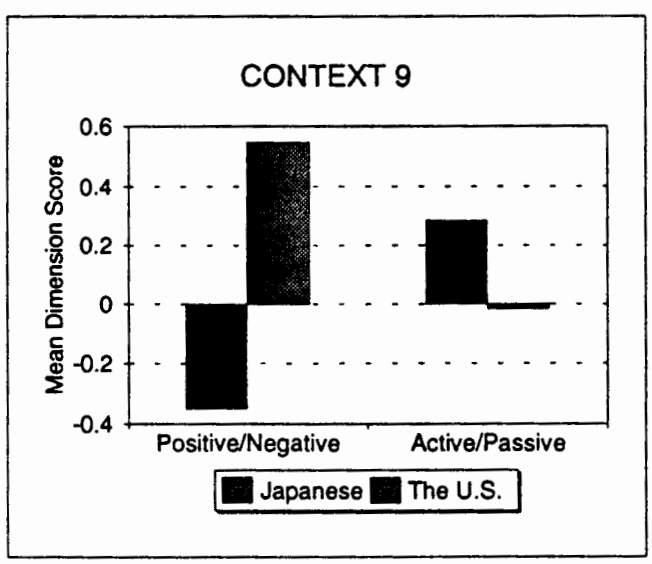

Figure 15. Silence of your Japanese friend.

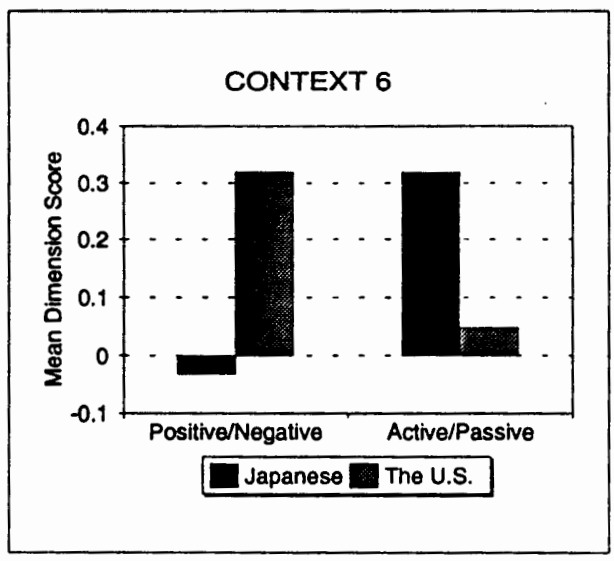

Figire 12. Silence of your teacher during a class.

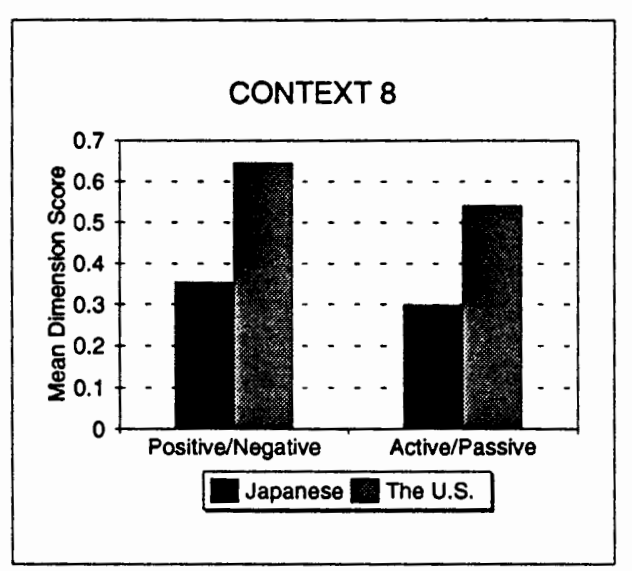

Figure 14. Silence when you are alone.

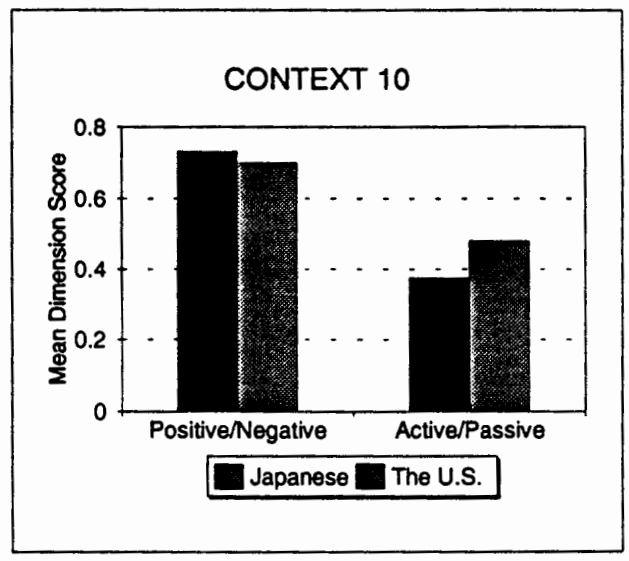

Figure 16. Silence when you are practicing Japanese arts. 
interpret silence as significantly more active in four contexts: negotiating a grade with a teacher, teacher's silence during a class, silence in front of your boss, and silence of your parents in front of you. The U.S. subjects interpret silence as significantly more active in one context: silence when you are alone. The four contexts in which Japanese interpret silence as more active have to do with hierarchical authority, suggesting that silence is an active part of hierarchical authority relationships for Japanese, but not really for the U.S.

Some differences were found in MDS mapping between Japanese and the U.S. The use of silence related to the following concepts may differ between Japanese and the U.S.: save-face, shy, reserved, daydream, comfort, tranquility, peaceful, and doubtful. 
CHAPTER V

DISCUSSION AND CONCLUSION

The purpose of this research was to study the interpretation of silence among Japanese and U.S. subjects and promote an understanding of Japanese and U.S. communication patterns. Two hypotheses were generated based on the previous literature. They were: H1, subjects' concepts of silence will resemble the concept of silence of other subjects with the same nationality more than they will resemble that of other subjects from different nationalities. Hypothesis 2, the longer the U.S. subjects have studied Japanese cultural practices, the more they may be similar to Japanese in how they interpret silence than the U.S. subjects who have not studied Japanese cultural practices.

Research Questions were: what were the differences in interpretation of silence between Japanese and U.S. subjects?; what is the underlying structure of the concept of silence as it is interpreted by Japanese and U.S. subjects?: what are the differences in interpretation of silence between males and females? In this study, subjects were presented 35 cards on which each had silence related words written, and were asked to sort the cards 
into piles by making any kind of association among words. After the cards were sorted, subjects were asked to identify which pile of words is associated with each of ten different contexts provided by the researcher.

Through this research, Japanese and U.S. subjects conceptualized the idea of silence by using silencerelated words, sorted the silence-related words into clusters, and assigned those word clusters into the ten contexts in which silence occurred. This chapter discusses the interpretation of data analysis, limitations of the study, recommendations for future study, and the conclusion.

\section{DISCUSSION}

Overall, the results suggest that Japanese were more similar among themselves in conceptualizing silence than they are to U.S. subjects, and U.S. subjects were more similar among themselves in conceptualizing silence than they are to Japanese. Thus, Hypothesis 1 was supported in this study.

An attempt was made to examine the acculturation process of the U.S. subjects to the Japanese interpretation of silence by comparing those who had been learning silence-centered Japanese cultural practices for a long time with those who had not learned. Significant 
differences were found in only two out of eighteen contexts. These contexts were: discussing the holidays with your intimate friend and silence of your same sex intimate friend in the active/passive dimension. Since very few subjects of either nationality had experienced Japanese arts long enough, it was not possible to test Hypothesis 2 adequately. Thus, no conclusions regarding H2 could be drawn.

Differences due to sex were also examined in the research. The result from subjects' weights revealed that the degree of using the positive/negative and passive/active dimensions are similar between Japanese males and females, and similar between U.S. males and females. This is supported by the attribution theory and the discussion by Robbins et al. (1988). In attribution theory, it is assumed that people attempt to determine the causes of behavior, and people assign causes systematically (Littlejohn, 1989). Components of communication are learned and socially patterned by the contexts of social groups (Robbins et al., 1978). Interpretation of silence attributed by Japanese and that of U.S. subjects were based on their own cultural systems patterned by the contexts of social groups. Therefore, interpretation of silence of each nationality was similar to each cultural group itself. 
Differences were found between Japanese females and U.S. females, that is the U.S. females use the positive/negative and passive/active dimensions more than Japanese females. The differences between Japanese males and U.S. males were small. As Hecht et al. (1990) stated, females are more attentive to silent, nonverbal cues than males. Therefore, Japanese females and U.S. females showed more differences in interpreting silence than differences between Japanese and U.S. males.

\section{(RO1) Differences in interpretation of silence between Japanese and U.S. subjects}

Mean Dimension Scores Associated with each Context.

Ten contexts were plotted on two dimensions, according to the mean scores associated with each context. As figure 4 shows, Japanese and U.S. subjects seem to interpret silence differently, according to the interaction contexts.

For Japanese, in some contexts, silence is interpreted as quite negative. The context can be when the speaker utilizes silence as one of the ways to avoid a negative outcome. Japanese may remain silent when they want to avoid conflict and embarrassment (Graham et al., 1983). In this case, the listener and the speaker may become uncomfortable with the silence, because it is expectable to have a negative outcome if the speaker 
spells things out.

If Japanese interpret silence negatively, they may want to know what the speaker's silence means. Therefore, ishindenshin: catching on quickly to another's intention before the thought is completely expressed verbally and sasshi: surmise or guess are commonly used in Japanese communication. Nonverbal intuitive communicative practices such as sasshi and ishindenshin lead to nondialectical oriented interpersonal relations among Japanese people (Ishii et al., 1991).

The U.S. subjects had a tendency to interpret silence depending on contexts more positively than Japanese in almost every context. This may seem inconsistent with most of the literature which suggests that people from the U.S. are uncomfortable with silence where 'talk' is expected (Barnlund, 1989; Nishida, 1989; Deutsch, 1983; Fisher, 1980; Graham et al., 1983; and Hellweg et al., 1991). However, the ten contexts used in this study do not necessarily indicate that 'talk' is expected.

Since the contexts in the study are mostly neutral, the result in this study suggests that the U.S. subjects interpreted silence as something positive in relatively neutral contexts, i.e., the contexts which do not specifically necessitate the verbal participation.

If the context requires speech i.e., during a 
negotiation, people from the U.S. may interpret silence rather negatively. Deutsch (1983) stated that U.S. negotiators tend to take Japanese silence during negotiation as presenting a noncommittal attitude. On the other hand, this study reveals that there do exist contexts in which the U.S. subjects interpreted silence as something positive and indicates that they are not necessarily always uncomfortable with silence.

A boss's silence in front of you was the only context where the U.S. subjects interpreted silence negatively. This silence may function to regulate the relationship between employee and employer. According to SavilleTroike (1985), employees may remain silent in front of their employers (boss') when they consider themselves being subordinates to employers. This may suggest that employees expect their employer (boss') to do the talking in a normal situation, and that employers's (boss') talk indicates that the working relationship is going fine. Thus, when their employer (boss) is silent, the employees may interpret it as if something wrong had occurred in their relationships.

Japanese placed boss' silence, teacher's silence, friend's silence, and partner's silence in the negative dimension. The fact that the Japanese subjects interpreted silence as negative indicates that when 
silence occurs they consider the silence as a sign that something wrong is going on in a given situation.

The tendency toward negative interpretation of silence by the Japanese subjects may be explained by the concept of sasshi (surmise or guess). When something problematic takes place in a given situation or relationship, the person who is experiencing uncomfortableness may remain silent instead of expressing it through verbal communication. Words are thought to be deceptive (Barnlund, 1989). The other person is expected to guess (sasshi) what underlies the silence.

Comparison of Japanese and U.S. subjects in Contexts by Utilizing MDS.

Differences in the interpretation of silence between U.S. and Japanese subjects were examined. The t-test was used to find differences in the way the U.S. and Japanese subjects interpret silence, utilizing how they associate words in the ten contexts in the MDS mapping. Significant differences were found in comparing mean scores of Japanese and U.S. subjects. There are significant differences in almost every single context in the active/passive and positive/negative dimensions (see figure 7 to figure 16).

(C1) Silence while deciding what to do during the holidays with your intimate friend was significantly 
different.

The U.S. subjects interpret the silence in the same context as highly positive in private/outer quadrant, whereas Japanese interpret it as negative. One's action may be understood within the contexts of an episode (Pearce et al., 1980). In the hierarchy of contexts, Littlejohn (1989) discussed that the episode context involves events which are defined by an individual who carries different speech and nonverbal behaviors. In the U.S. nonverbal behavior, the context: silence of intimate friends while discussing how to spend a holiday may be interpreted/defined positively whereas that of Japanese is interpreted negatively. As kato et al. (1991) discussed, the U.S. communication tends to depend on verbal expression. Therefore, the silence may be interpreted as simply as the speaker does not have things to say.

(C2) Silence while negotiating the changing of your grade with your teacher was significantly different. Japanese interpret the silence in this context as active and negative. The U.S. subjects interpret it as passive and positive silence. (C6) Silence of your teacher in front of you was significantly different. Japanese interpret it as negative and more active than the U.S. subjects do. The U.S. subjects interpret it as positive and less active than Japanese. 
Overall, the U.S. subjects tend to interpret silence of their teacher as positive and less active, whereas Japanese interpret it as negative and active. This suggests that the U.S. subjects interpret teacher's silence rather positively, and they may interpret teacher's silence as the teacher's inner/private activity.

In expressing one's own view, equity of participants, freedom from social coercion, and free expression of feelings are required in the U.S. (Burton et al., 1979). Therefore, U.S. students may be more assertive than Japanese in asking about the change of a grade, and feel less uncomfortable with silence than Japanese students.

(C3) Silence of your partner in front of you was significantly different. The U.S. subjects interpret it as positive and less active than Japanese. The U.S. subjects may interpret silence of their partner as placid. Baker (1955) suggested that silence is interpreted as being content between lovers, where words are unnecessary and silence does not create uneasiness.

Japanese interpret it as negative and more active than U.S. subjects. The Japanese negative interpretation of silence of one's partner may be accounted for by the expectations which both parties bring into the relationship between Japanese males and females. One of the expectations may be that both parties want the other 
party to figure what they are thinking in their mind without verbalizing their thoughts (Ramsey et al., 1983). If one is not used to the expectation to read the other person's mind, the silence may create tension between the one who is silent and the one who is to figure.

When something problematic occurs in a given situation or relationship, a Japanese may remain silent without vocalizing it with the assumption that the message that there is something wrong will be understood by the other person. As Ramsey (1985) discussed, Japanese may think that explicitly stating an opinion may bring more negative effects if the relationship is their primary concern. Furthermore, if the other person fails to guess the message carried through the silence, it will frustrate the person who chose to be silent. This is because Japanese tend to assume shared communicative situations, i.e., what is appropriate behavior in a certain situation (Midooka, 1990). Therefore, Japanese may use sasshi (surmise) or heart-to-heart communication more than U.S. subjects.

(C4) Silence of your boss at work in front of you was significantly different. Japanese interpret it as negative and slightly more active silence than U.S. subjects. The U.S. subjects interpret it as negative and less active silence than Japanese. Interestingly, both 
Japanese and U.S. subjects plotted this context in the negative/active quadrant. This result suggests that both Japanese and U.S. subjects are not comfortable with their boss's silence.

Interpretation of silence varies depending on the situations and the relationship of a speaker and a listener. In the hierarchy of contexts (Littlejohn, 1989), the self-concept context is one's sense of how to perceive oneself. Since employees perceive themselves as being subordinates, it is hard for them to be careless about their boss' silence. Therefore, employees may interpret boss' silence as less positive, and attribute silence to negative messages.

A boss's silence may indicate merely a conversational switching pause. The duration of switching pauses varies depending on contexts, and on some occasions they are perceived as too long and awkward by a speaker and a listener (McLaughlin, 1984). The perceiver is encouraged to interpret silence based on what is vocalized right before it (Saville-Troike, 1985).

(C5) Silence of your father or mother in front of you was also significantly different. Japanese interpret it as slightly more active and slightly less positive than U.S. subjects. Both Japanese and U.S. subjects plotted this context in the passive/active dimension in the 
private/outer quadrant. This result suggests that both Japanese and U.S. subjects tend to interpret their parents' silence as a private and inner/self-enlightened activity. As Samovar et al. (1991) stated, the relationship among communicators influences the interpretation given to the silence. In the hierarchy of contexts (Littlejohn, 1089), "the relationship context includes mutual expectation among members of group" ( $p$. 124). The expectation of Japanese and people from the U.S. to their parents may be somewhat similar, therefore they interpret their parents' silence alike.

(C7) Silence of your same sex intimate friend was significantly different. Japanese and U.S. subjects placed this context in the private/outer quadrant. Although both Japanese and U.S. subjects interpret the silence in this context as active, Japanese interpret it as less positive than U.S. subjects. This may suggest that Japanese may be concerned with the silence of their intimate friend, because silence signals that there is something negative. As Lebra (1987) stated, silence is vague and confusing unless interactants know each other enough to communicate without exchanging verbal information regarding their thoughts and feelings. Japanese may attribute their intimate friends' silence according to somewhat negative thoughts and they may 
interpret their friends' silence as indecisive, indirect, and a non-committal attitude. The attributed cause has impact on the perceiver's own feelings (Kelley, 1972).

(C8) Silence when you are alone was significantly different, and both Japanese and U.S. subjects placed this context in the private/outer quadrant. Japanese interpret it as less passive and less positive than U.S. subjects. The U.S. subjects interpret it as more active and more positive than Japanese. Both Japanese and U.S. subjects may interpret silence when they are alone as an inner meditative moment. When Japanese and U.S. subjects are alone, they may follow the following proverbs: 'silence is a virtue', and 'silence is golden'. The meaning attached to the particular use of silence may not vary crossculturally (Braithwaite, 1990).

\section{Summary.}

In general, Japanese are more likely to interpret silence as active and negative, and silence can be viewed as an active mean of communication. This is especially true when the Japanese subjects are either with a friend, a partner, or with a person in a position of power, such as a boss or teacher.

For Japanese, silence may have a communicative meaning, and the other person is often expected to know what the silent person tries to get across. This 
communicative use of silence may lead to the expectation that one should figure out unsaid messages and that one does not have to spell out what the message is (Johnston, 1980). Japanese tend to expect that feelings and wishes will not be expressed (Ramsey, 1985). Therefore, instead of expressing negative feelings verbally, Japanese may tend to utilize silence as an active means to express such feelings to the outer world. Furthermore, since Japanese tend to interpret silence negatively, they actively try to guess what underlies silence.

Individuals from the U.S., on the other hand, are more likely to interpret silence as less active and more positive than Japanese, that is to say, as private and inner. Although people from the U.S. may occasionally use silence as a communicative tool (i.e., the moment to experience the holy spirit), as Kato et al. (1991) discussed, ordinarily it is expected that feelings and wishes will be expressed verbally. Silence is more likely to be interpreted merely as a sign that the other person either has nothing to communicate or is still thinking, and if there is something to communicate, she/he will communicate it through verbal communication. Without feeling expected to guess the other's meanings, people from the U.S. are less likely to feel anxious about the other person's silence, and will tend to attribute it to 
private and inner causes.

The Comparison between Japanese and U.S. Subjects on MDS Mapping.

In the comparison between Japanese and the U.S. MDS mapping, some words were moved from one quadrant to another. Comfort, peaceful, and tranquility were placed in the positive/active dimensions in the private/outer quadrant among the U.S. subjects, and were placed in positive/passive dimensions in the public/inner quadrant among Japanese. Comfort, peaceful, and tranquility are related to philosophy of Japanese arts, especially with chanoyu (tea ceremony).

Tranquility is one of the concepts to characterize the philosophy of chanoyu (Sen Soshitsu, 1966). Chanoyu is conducted during the silent peaceful moment. Therefore, Japanese may be expected to plot comfort, peaceful, and tranquility on an active dimension, but they placed them on a passive dimension in the public/inner quadrant. If Japanese are not familiar with chanoyu, they may relate those concepts with public/inner interpretations which tend to focus on keeping harmony with others where sticking out is harmful, because they placed those words in the public/inner quadrant in the passive dimension.

The U.S. subjects placed them in the active 
dimension. This suggests that the U.S. subjects interpret comfort, tranquility as more active expressions of silence than do Japanese. The U.S. subjects may relate those concepts to particular contexts, such as at the church, where silence is preferred (Lippard, 1988).

Daydream was located in the positive/passive dimension in the public/inner quadrant among the U.S. subjects, and is grouped with save-face, reserved, passive and wait for a turn. Daydream is located in the negative/passive quadrant, and grouped with preoccupied among Japanese. Since daydream is placed on a different quadrant by Japanese and U.S. subjects, and it is grouped with different words, its concept may be different between Japanese and U.S. subjects. The difference in interpreting daydream between Japanese and U.S. subjects may be because of the different connotation of the word, daydream.

Doubtful was placed in the negative/passive quadrant by U.S. subjects, and it is grouped with indecisive. Doubtful is placed in the negative/active quadrant by Japanese, and it is grouped with dislike, threat, and disagree. This may suggest that for U.S. subjects, the state of being doubtful may exist within the silent person, having little affect on the interlocutor, whereas the state of being doubtful may have a certain amount of 
impact on the interlocutor. The act of doubting stays in one's subconscious level among the U.S. subjects, whereas the act of doubting may come out of one's mind and trigger conflict in the communication among Japanese.

Save-face was placed in the positive/passive dimension in the public/inner quadrant by the U.S. subjects and was placed in the positive/active dimension in the private/outer quadrant by Japanese. Graham et al. (1983) stated that Japanese remain silent when they want to avoid conflict, embarrassment and to save-face. For Japanese, being silent is associated with saving-face, and silence can be used as an active communication tool. Save-face is clustered with confidence and dignity in the Japanese MDS solution, which can be interpreted as saveface serves to assure one's confidence and dignity.

The U.S. subjects may have a different meaning for save-face. When the U.S. subjects remain silent to save face, they may value being silent, to show a reserved behavior. Perhaps saving-face is a passive behavior for the U.S. subjects because of the underlying assumption that she/he could have chosen to speak but she/he opted not to speak in order to avoid embarrassment.

In Japanese culture, silence and save-face are active, communicative gestures. Moreover, Japanese may be expected to consistently be attentive to what is unsaid, 
thus retreating into private reverie (i.e., daydreaming and preoccupied) may be seen negatively. In the U.S. culture, silence and save-face are simply a matter of avoiding an affect such as embarrassment. It has no particular communicative function, such as figuring the other's mind or sympathizing with the other's emotion.

In the U.S. culture, it is often acceptable to retreat into a private reverie, and if it doesn't last too long, it will often not even be noticed. Similarly, shyness, daydream or reserve is often viewed as a sign of respect, or as a pause in a conversation, especially in a hierarchical situation; i.e., hierarchical subordinates in an organization are expected "to be seen and not heard", and "to speak when spoken to". Thus a shy silence, daydream and reserved may be positively interpreted as respectful and considerate in America. On the other hand, shy silence, daydream, reserved may be interpreted as a gap of communication where a person is silently observing who will carry on the conversation next, and interpreted negatively in Japan.

(RO2) Underlying structure of the concept of silence as it is interpreted by Japanese.

Most of the words were clustered to the right or left side on the passive/active line which connects wait for a turn, and warning in Japanese MDS (see figure 5). This 
may suggest that those two words are key words in the Japanese interpretation of silence. 'Waiting for a turn' is in other words 'waiting for a pause which will be created by a communication partner'. As Lebra (1987) discussed, Japanese common strategy of silence is the use of a pause. The Japanese listener gives space, or a silent interval while interacting with others in order to interpret the opinions and feelings of the speaker (Naotsuka, 1992). Ma (silence space) is utilized in their conversation. Ma forms the concept of silence (Mare, 1990). Along with ma, interdependence is an important concept in the Japanese interpretation of silence. Their communication is based on an interdependent relationship, where the speaker expects the listener to take the initiative of understanding the speaker's intention during a silent moment.

Along with wait for a turn, warning may be considered as another key concept in the Japanese interpretation of silence. While wait for a turn was located in the passive/positive dimension in the public/inner quadrant, warning was found in the negative/active quadrant. This may suggest that warning connotes one of the negative/active silences in Japanese communication. warning is located between save-face and conflict. Warning is perceived as less positive than save-face 
because it is threatening. On the other hand, warning is less negative than conflict because warning may imply willingness to repair a problematic situation.

A cluster of words which includes "meditating, spiritual, insight, pondering, figure, self-enlightenment, confidence, dignity, and save-face" are plotted in the positive/active dimension in the private/outer quadrant (see figure 6). Diagonally across from those words, shy, reserve, passive, indirect, non-committal attitude, and indirect are grouped in the negative/passive quadrant. The former cluster relates to the concepts of ishindenshin, haragei, and sasshi.

Ishindenshin (intuitive sense) refers to catching on quickly to another's intention or desire before the thought is completely expressed verbally (Ramsey, 1985). The words, meditate, spiritual, insight, figure, ponder, indirect, and non-committal attitude explain the concept of ishindenshin well. For example, a Japanese husband who has been married to a wife for a long time may communicate like "are ga hoshii, hora are" (I need that, you know, that thing). The wife should be able to find "are" (that) for her husband by figuring what they were previously talking about, by using her intuition, by meditating or pondering for a second. Their conversation may look like they are not committed to each other, because the husband 
is not telling her exactly what he is looking for, and the wife is not asking him to explain what he wants more specifically.

Haragei (hara, belly and gei, act) refers to wordless communication used when the topic is delicate and the speaker can't find the words (Saville-Troike, 1985). It is understood as heart-to-heart communication, guessing the inner thoughts of the other by nonverbal means (Ramsey \& Birk, 1983). The words, confident, dignity and saveface, pondering, indirect, reserved, indecisive, and passive explain its concept. For example, if the topic is delicate, Japanese people try to touch the topic indirectly (Hoshi, 1987). When one is indecisive, being silent may save his/her face, and he/she may remain with dignity and confidence. In order to guess the other's mind properly, they may ponder while being engaged in haragei, and they may look indecisive.

Sasshi means to surmise or guess. Spiritual, insight, self-enlightenment, reserved, passive, and indirect are well associated with the concept of sasshi. For example, when a person has lost his/her daughter as the result of an accident, visitors who have experienced a similar loss may say, "okimochi osasshi shimasu" (I surmise your feeling). This means that visitors are showing their sympathy to him/her from the bottom of their 
heart, and they can feel his/her emotional struggle by using their insight, spirit, or their self-enlightenment in a passive and reserved way.

The word patience is plotted close to appropriate and polite in MDS. The association of patience with appropriate and polite may be explained by the Japanese tendency toward making a point toward the end. Hall (1977) called this "a roundabout way" of communication. Ramsey et al. (1983) attributed this roundabout way of communication to the sentence structure, i.e., the verb comes at the end of the sentence. Doi (1988) suggested that the fact that the verb comes at the end allows the speaker to be obscure because he/she can change his/her point while speaking and can consider what is appropriate to say. When a person is talking, a listener needs to wait until the person finishes talking, because the listener doesn't know the speaker's point till the end. Waiting until the speaker finishes takes patience on the part of the listener and is considered polite and appropriate in Japanese communication.

Conflict is mapped in the higher part of the negative dimension in MDS with inappropriate, anxiety, confused, doubtful, dislike, disagree, threatening, and impolite. Japanese people try to avoid direct confrontation in communication. Directness may mean rudeness for Japanese 
(Hoshi, 1987). The Japanese may think that direct expressions of emotion or explicit statements of an opinion may bring a more negative than positive effect if the relationship is their primary concern (Ramsey, 1985). From this point, direct confrontation is considered impolite in the Japanese strategy of communication.

(RO3) Underlying structure of the concept of silence as it is interpreted by the U.S. subjects.

In the U.S. MDS map, words are grouped as positive clusters and negative clusters. The U.S. subjects placed wait for a turn closer to shy, reserved, and passive. Tannen (1985) states that the social consequence of pausing is to make the impression of being one sort of person rather than another. The U.S. subjects may interpret waiting for a turn as a sign of being reserved, shy, or passive.

The following were clustered together between the public/inner and the private/outer quadrants: waiting for a turn, save-face, agree, polite, appropriate, patience, dignity, and confidence. This cluster may suggest that the silent moment functions as a pause to give the speaker time to think, and the listener time to comprehend. One person's silence is another person's pause (Tannen, 1985). By pausing, the speaker may gain the chance to organize appropriate and polite talk; the speaker may save-face; 
may save his/her confidence; and the listener patiently waits for the speaker to talk while comprehending his/her points.

The cluster, waiting for a turn, save-face, agree, polite, and appropriate, patience, dignity, and confidence may be also related to a socio-cultural silence. The cluster is related to the characteristics of each social order regarding when to be silent and when not to be silent (Bruneau, 1973). Human behavior is based on the rules of the culture which each person belongs to (Nishida, 1989). People from the same culture may identify when to be silent and when not to be silent by learning culturally embedded rules. The U.S. subjects may remain silent when they want to be polite, agreeable, confident, waiting for a turn, and save-face.

Comfort, peaceful, spiritual, self-enlightenment, meditate, insight, and tranquility are clustered together. These were grouped close to figuring and pondering in the positive/active dimension in private/outer quadrant. They are positively valued silences and show their tendency to connect silence with spiritually related words. For example, Quakers experienced the holy spirit through silent gathering, and they considered silence as the highest achievement of receiving the holy spirit (Lippard, 1988). In a religious context, people from the U.S. may 
feel comfort, peace and meditation. This tranquil moment may be considered as the time when they reach selfenlightenment.

Conflict was clustered with dislike, inappropriate, disagreement, impolite, threatening, confused, anxiety, and warning in the negative/active dimension. This grouping is almost the same as the Japanese. This result may suggest that both Japanese and U.S. subjects interpret conflict in a conversation negatively, and it is impolite, inappropriate, and should be warned against. Japanese and U.S. communication strategy may identify threatening, disagreement and conflict as confused and inappropriate things which create uncertainty. As Johannesen (1974) mentioned, by remaining silent, people may avoid discussion of a controversial subject, and they avoid conflict so as not to hurt others' feelings.

Preoccupied, non-committal attitude, indirect, indecisive, and doubtful are grouped in the negative/passive quadrant. This group remind us of a hesitation pause in the linguistic usage of silence. A hesitation pause indicates a change of speaker (McLaughlin, 1984). As Chef (1985) states, sometimes speakers hesitate while they are deciding what to say or how to explain themselves. People process their ideas in this moment of hesitation (Bruneau, 1973). During the 
hesitation pause, people may be doubting the opponent's point. Their silence may be seen as a non-committal attitude, because they are presenting indirect interaction with the communication partner.

(RO4) Differences in interpretation of silence between males and females.

(RO5) Differences in interpretation of silence, due to differences in sex among Japanese.

(RO6) Differences in interpretation of silence, due to differences in sex among U.S. subjects.

Differences due to sex were examined. The result from subjects' weights showed that there was no significant difference between males and females in using the positive/negative and active/passive dimensions. No significant difference was observed in the averaging interpretation of silence of overall contexts.

However, a significant difference was found in the interaction between sex and nationality in examining subjects' weights. The U.S. females use the positive/negative and active/passive dimensions more than Japanese females. The difference between Japanese males and U.S. males was small.

The result may suggest that Japanese males and U.S. males are similar in conceptualizing the idea of silence and that their ways in assigning meaning to silence could be almost identical. In CMM by Pearce et al. (1980), they 
discussed constitutive rules and regulative rules. constitutive rules are rules of meaning used by communicators to understand the event (Pearce et al., 1980). Regulative rules are rules of action used to determine how to respond (Pearce et al., 1980). In conceptualizing the idea of silence, Japanese and U.S. males may use similar constitutive rules and regulative rules.

When the context factor is taken into account, Japanese males are more likely to interpret silence as active and less likely to interpret silence as positive; and U.S. males are more likely to interpret silence as positive and less likely to interpret silence as active.

The result from subjects' weights shows that the U.S. females use the positive/negative and active/passive dimensions more than Japanese females. This may suggest that U.S. females are more straightforward in assigning the meaning of silence when they face silence, and they interpret it as more positively, more negatively, more actively, or more passively than Japanese females. Japanese females may interpret silence as a natural phenomena and interpret silence neutrally rather than assigning a specific meaning. This is consistent with the literature: as opposed to generally outspoken western women, many women in eastern culture see their silent role 
as natural (Ishii et al., 1991).

Compared to Japanese males, Japanese females and U.S. males, U.S. females used the positive/negative and passive/active dimensions more. Compared to Japanese males, U.S. females, and U.S. males, Japanese females used the positive/negative and passive/active dimensions less. This suggests that U.S. females have a more explicit conceptualization of silence than Japanese males, Japanese females and U.S. males. If U.S. females tend to interpret silence as a communicative failure as Barnlund (1989) suggested, they may interpret silence rather explicitly than neutrally.

The result may propose that Japanese females tend to conceptualize the idea of silence more neutrally than Japanese males, U.S. males, and U.S. females. As Wagatsuma (1984) stated, "Japanese social relationships are based upon interdependence among people, and a dependent attitude (amaeru) is ... at times encouraged" $(p, 372-373)$. Since interdependence is socially accepted, Japanese females may take a neutral stance in conceptualizing silence, and encourage the listener to take the initiative of understanding their intention during a silent moment.

When contexts are considered, Japanese females are more likely to interpret silence as active and less likely 
to interpret silence as positive; U.S. females are more likely to interpret silence as positive and less likely to interpret silence as active. Yamada (1989) and Watanabe (1990) studied turn-taking and compared its usage between U.S. and Japanese females. The U.S. subjects attempted to express their opinions through autonomous turn-taking (Yamada, 1989). If silence functions as the turn-taking, it means 'pause' in the conversation for U.S. subjects, and it is a time to take a turn and talk. While the Japanese wait a turn, the U.S. subjects may take a turn unknowingly (Watanabe, 1990). As a consequence, the Japanese end up sitting silently throughout the discussion although they have something to add. Japanese are actively engaged with the discussion, because they want to express their opinions. Silence in this context is not passive, it is rather active.

\section{THREATS TO VALIDITY}

The main purpose of this study was to examine the interpretation of silence between Japanese and U.S. subjects. First, a study of the acculturation process of the U.S. subjects who have studied Japanese cultural practices, was attempted. Unfortunately, the research was unable to provide sufficient information for this, due to the small number of subjects who studied Japanese arts 
long enough.

second, the card sort procedure may not necessarily generate the conceptualization/interpretation of silence because there is no guarantee of the subjects sorting cards while they are thinking about silence, although that was encouraged during the research. Also, there is a possibility that some subjects did not know the meaning of all the words. The subjects may not be interested in asking any questions they may have about the research because they may have been overwhelmed by the task, which was sorting 35 words in groups, and making associations of the groups of words with ten different contexts.

Third, in this study, English words used for the research were translated into Japanese, and the backtranslation was done by a Japanese professor and two graduate students. Although the back-translation was conducted, there is a possibility of linguistic differences in translating English into Japanese. Furthermore, each Japanese and U.S. subject may have assigned different connotations to words when they sorted cards. Therefore, Japanese translations of English words may not carry the sense of English meaning and vise versa. Fourth, there is a possibility of Japanese and U.S. subjects assigning different meanings to "silence", "chinmoku" in Japanese. Silence is translated as 
"chinmoku" in this study. If silence functions as a pause in the conversation, it may be translated as "ma" in Japanese. "Chinmoku" and "ma" carry slightly different meanings, and if silence is translated as "ma", different interpretations may have been elicited among Japanese.

Finally, as an operational limitation, words used for the card sort and ten contexts for describing the usage of silence may not be as valid as some other possible words which may signify silence better, or some sort of context which possibly describes silence in a different way. Also, a context itself may have a negative setting and may not be interpreted as a neutral setting by subjects (e.g. in $\mathrm{C} 2$ : silence while negotiating a change of a grade with your teacher, negotiating a change of a grade may be perceived as socially inappropriate in Japanese society).

\section{FUTURE RESEARCH}

The findings of this study and limitations suggest directions for future study. First, due to the linguistic differences between U.S. and Japanese subjects, there is the possibility of some different translations of "silence" in Japanese. "Silence" can be translated as "ma" and "chinmoku" depending on the definition of silence. If this research used "ma" as translating 
silence, Japanese may have presented different interpretations in explaining the concept of silence. Therefore, future study should use "ma" (silent interval) in translating/defining "silence", and examine whether there is any difference in interpretation of silence between Japanese and U.S. subjects from the presented study .

Secondly, significant differences in the interpretation of silence between Japanese and U.S. subjects were found depending on what contexts they faced when confronting silence. Only ten contexts were provided for the study, and there may be diverse contexts which will provide different findings. However, those ten contexts were chosen from literature where silence was studied, and they may represent the contexts where interpretations of silence get attention.

As for providing different contexts for future study, the researcher suggests the following concepts to be included: save-face, group oriented and individualism, inter-dependent and independentness, and keeping harmony. For the intercultural study, it is encouraged to use contexts which have intercultural settings of people from different cultures. Furthermore, it is worth examining the interpretation of silence in various contexts in which either talk or silence is expected. Examples are: silence 
in class, silence when group discussion is almost coming to an end, and silence at a business meeting.

Third, due to operational difficulties, the study did not produce the Multidimensional Scaling (MDS) solution of male and female subjects, subjects who have studied Japanese cultural practices (tea ceremony, flower arrangement, calligraphy, and karate), and subjects who have not studied those Japanese cultural practices. Therefore, differences in associating silence related words among (a) males and females, (b) subjects who have studied Japanese cultural practices, and (c) subjects who have not studied cultural practices were not observed. It is encouraged to examine MDS of the above variables for an in-depth study of the conceptualization of silence. It is also suggested to use larger samples of populations practicing Japanese cultural arts, and larger samples of practicing it for a long period in order to examine the acculturation process properly. It may be interesting to compare Japanese who have never been in the U.S. and Japanese who have been in the U.S. for a long period to study the acculturation process among Japanese. This can also apply to the study of the acculturation process among U.S. subjects by comparing the U.S. subjects who have been in Japan for a long period, and those who have never been in Japan. 


\section{SUMMARY OF FINDINGS}

Culturally specific interpretations of silence were studied, comparing Japanese and U.S. subjects. The greatest difference in the interpretation of silence between Japanese and U.S. subjects was found in the way they associate groups of words with contexts. The U.S. subjects had a tendency to interpret silence, depending on contexts, as more positive than Japanese. Japanese show the tendency to interpret silence, depending on contexts, as more active than U.S. subjects.

The Japanese listener gives space, or a silent interval while interacting with others in order to interpret the opinions and feelings of the speaker (Naotsuka, 1992). This may be because Japanese often utilize sasshi in interaction, and they are expected to "know what the other wants to say without being told", (i.e., figuring what is unsaid). Moreover, according to the literature (Graham et al., 1983; Ramsey, 1985; and Rowland, 1985), when conflict occurs, Japanese tend not to communicate the negative feelings verbally. Instead, they may remain silent. From the interpreter's viewpoint, Japanese may be prone to perceive silence as a sign of negativity.

The U.S. subjects are only occasionally faced with 
this expectation, and it is usually verbally marked (i.e., "you know what I mean" or "just think about it for a minute"). 'What was said' is meaningful and it is not common to try to figure out what may be behind the 'word' of the sender in the U.S. culture (Kato et al., 1991). The U.S. subjects are more likely to interpret silence as less active. Moreover, in contexts where there is lack of expectation for talk, silence may be perceived by the U.S. subjects as a moment to think, as a way of "giving me a little space," and may be interpreted as relatively positive, even in a situation of dealing with a boss or teacher who are considered hierarchically higher.

The result that the U.S. subjects interpret silence as more positive than Japanese in various contexts, appears to be contrary to many of the discussions in the literature claiming that people from the U.S. are uncomfortable with silence (Barnlund, 1989; Nishida, 1989; Deutsch, 1983; Fisher, 1980; Graham et al., 1983; and Hellweg et al., 1991). This study suggests that there are contexts in which the U.S. people are comfortable with silence. The claim that U.S. people are uncomfortable with silence is too simplistic and generalized.

In Japanese culture, save-face and silence are active communicative gestures that are performed deliberately and are expected to be properly interpreted. When silence is 
used to intentionally communicate something, it can create uncertainty if the listener is unable to figure what underlies the silence. In the U.S. culture, silence and saving-face are passive. Silence is often produced either because the speaker has not yet worked out what to say, or because there isn't anything that needs to be said. Saveface is simply a matter of avoiding a negative affect such as indecisiveness or embarrassment. Similarly, in the U.S. culture, it is often acceptable to retreat into a private reverie, but in Japanese culture, the listener is often expected to be engaged with others and figuring the other's mind, if it is necessary. Thus if silence has the quality of daydreaming, it is interpreted as non-committal attitude, but for U.S. subjects, it is interpreted as positive and appropriate silence.

\section{CONCLUSION}

As a cross-cultural study, this study used populations of native Japanese speakers living in Japan and English speakers living in the United States. Intercultural and cross-cultural studies tend to rely on Japanese samples living in the United States. However, this study provided more culture-specific data adding to the available information on Japanese communication styles. 
The study focused on the interpretation of silence by Japanese and U.S. subjects, and only a few empirical studies have been done. Therefore, the study contributes to the under-researched area in the empirical study of silence in human communication.

This study suggests that both Japanese and U.S. subjects interpret silence depending on contexts. For Japanese, silence has a symbolic meaning, and the listener is often expected to figure out the underlying meaning of silence, and sasshi (surmise or guess) is encouraged. This communicative use of silence may lead to a feeling of uncertainty when a person is not accustomed to figuring out the person who is remaining silent.

U.S. subjects, on the other hand, are more likely to interpret silence as positive and less active, that is to say, as private and inner. In the U.S. culture, it is expected that feelings and wishes will be spoken. Thus, silence is more likely to be interpreted merely as a sign that the other person either has nothing to communicate, or is still thinking and will communicate his or her wishes or feelings. Feeling less need to guess the underlying meaning of silence, the U.S. subjects are less likely to feel anxious about the other person's silence, and will tend to attribute it to private and inner causes. The underlying structure of the concept of silence as 
it is interpreted by Japanese is possibly based on the following functions: (a) silence is actively interpreted in Japanese communication, (b) silence may be utilized to conceptualize social behaviors such as save-face, and (c) silence can create uncertainty due to the pressure of expecting the listener to figure the underlying meaning of silence, especially in a hierarchical relationship.

The underlying structure of the concept of silence as it is interpreted by U.S. subjects is perhaps based on the following functions: (a) silence is a private/outer activity, and the U.S. subjects are less likely to feel anxious about the other person's silence, and will tend to attribute it to private and inner causes, (b) a silent moment functions as a pause to give the speaker time to think, and the listener time to comprehend, and (c) silence merely means that there isn't anything that needs to be said.

Unlike most studies, this study suggests that the U.S. interpretation of silence is positive and less active. Talk is not everywhere valued equally. U.S. and Japanese subjects conceptualize silence in almost the same way, but depending on contexts, how they utilize it and how they interpret it are different. Appropriate and inappropriate usage of silence is based on knowing or not knowing social rules of when to speak and when not to 
speak. For example, the U.S. subjects may interpret silence as negative, when their cultural rules tell them it is a time to talk. This study raises the awareness of the importance of knowing the social rules and norms of when to speak and when to listen to the conversational partner in order to communicate effectively.

In conclusion, the findings suggest that Japanese interpret silence as a communicative symbol that must be actively interpreted, and this is consistent with most literature, however, the findings emphatically contradict the stereotype of the "vocal American", commonly depicted in the literature. The gap with the literature may be caused because many of the previous studies are based on anecdotal study and do not consider contextual aspects. This study raises the question of how many other widelyaccepted stereotypes will likewise turn out to be overlysimplified or counterfactual. Therefore, additional empirical research, preferably considering intercultural and cross-culture communication between Japanese and U.S. subjects, is clearly in order. 
Asante, M. K., \& Gudykunst, W. B. (1989). Preface: International and intercultural communication. In $M$. K. Asante., \& W. B. Gudykunst (Eds.). Handbook of international and intercultural communication. (pp. $7-13$ ).

Averill, M. (1913). Japanese flower arrangement [ikebanal: Applied to western needs. NY: John lane company.

Baker, S. J. (1955). The theory of silence. Journal of General Psychology, 53, 145-167.

Barnlund, D. C. (1989). Communication styles of Japanese and Americans: Imagines and realities. Barmount, CA: Wadsworth, Inc.

Basso, K. H. (1990). To give up on words: Silence in Western apache culture. In D. Carbaugh (Ed.). Cultural communication and intercultural contact. (pp. 303-320). Hillsdale, NJ: Lawrence Erlbaum Associates, Publishers.

Becker, C. B. (1986). Reasons for the lack of argumentation and debate in the Far East. International Journal of Intercultural relations, 10, 75-91.

Bacon, M. K., \& Ashmore, R. D. (1985). How mothers and fathers categorize descriptions of social behavior attributed to daughters and sons. Social cognition, 3(2), 193-217.

Betsumiya, S. (1983). Nihongo no rizumu to ma. [Rhythm of Japanese and 'ma']. In H. Minami (Eds.). Ma no kenkyu. [The study of 'ma']. (pp. 75-94). Tokyo: Kodansha.

Bieda, K. (1970). The structure and operation of the Japanese economy. Sydney, Australia: John Wiley and Sons Australasia Pty., Ltd.

Bolton, R. (1990). Listening is more than merely hearing, In J. Stewart (Ed.), Bridges not walls: a book about interpersonal communication (5th ed.). NY: McgrawHill, Inc. 
Blackton, R. (1986). A study of the correlation between the degree of acculturation and scholastic achievement and English gain of ESL students, grads 2-5, Beach School, Portland, Oregon. Unpublished master's thesis, Portland State University, Portland, OR.

Braithwaite, C. A. (1981). Cultural uses and interpretation of silence. Unpublished master's thesis, University of Washington, WA.

(1990). Communicative silence: A crosscultural study of Basso's hypothesis. In D. Carbaugh (Ed.). Cultural communication and intercultural contact. (pp. 321-327). Hillsdale, NJ: Lawrence Erlbaum Associates, Publishers.

Brandon, R. J., Malm, P. W., \& Shively, H. D. (1979). Studies in Kabuki. Hawaii: East-West center, Culture learning institute, A culture learning institute monograph.

Bruneau, T. J. (1973). Communicative silences: Forms and functions. Journal of Communication, 23, 17-46.

Brislin, R. W. (1981). Cross cultural encounter: Face to face interaction. New York: Pergamon Press Inc.

Burton, B., \& Kline, S. (1979). Habermas' theory of communication: A critical explanation. Quarterly Journal of Speech, 65, 412-428.

Cambra, R., Ishii, S., \& Klopf, D. (1978). Four studies of Japanese speech characteristics. Paper presented at the meeting of the Communication Association of the Pacific's International Convention, Tokyo, Japan.

Cathcart, D., \& Cathcart, R. (1988). Japanese social experience and concept of groups. In L. A. Samovar \& R. E. Porter (Eds.). Intercultural communication: A reader (5th ed.). (pp. 186-192). Belmont, CA: Wadswroth, Inc.

Chafe, W. (1985). Some reasons for hesitation. In M. Savilie-Troike \& D. Tannen (Eds). Perspectives of silence. (pp. 77-89). Norwood, NJ: Ablex Publishing Corporation.

Condon, J. C. \& Yousef, F. S. (1975). An introduction to 
international communication. New York, NY: Macmilian Publishing company.

Deutsch, M. F. (1983). Doing business with Japanese.

Canada: The New American Library.

Dillon, W. R. \& Goldstein, M. (1984). Multidimensional analysis. New York: John Wiley \& Sons Publishing Company.

Doi, L. T. (1982). The Japanese patterns of communication and the concept of amae. In L. A. Samovar \& R. E. Porter (Eds.). Intercultural communication: A reader (3rd ed.). (pp. 218-222). Belmont, CA: Wadsworth Publishing Company.

Ehrenhaus. P. (1988). Silence and symbolic expression. Communication Monograph, 55, 41-57.

- (1983). Culture and the attribution process:

Barriers to effective communication. In $\mathrm{W}$. $\mathrm{B}$.

Gudykunst (Ed.). Intercultural communication theory: Current perspectives. (pp. 259-169). Beverly Hills, $\mathrm{CA}$ : Sage Publications, Inc.

Fast, J, \& Fast, B. (1979) Talking between the lines: how we mean more than we say. New York, NY: The viking Press.

Fisher, G. (1980). International negotiation: A crosscultural perspective. Chicago, IL: Intercultural Press Inc.

Graham, J. L., \& Herberger, R. A. Jr. (1983). Negotiation abroad - Don't shoot from the hip. Harvard Business Review, $61,160-8$.

Greene, A. B. (1940). The religious use of silence. NY: Richard. R. Smith.

Goodman, P. (1971). Speaking and lanquage. NY: Random House.

Haga, K. (1991). Zenkou no chagiku: zokuikkoubutsu. [Chagiku of proper behavior: zokuikkoubutsu]. Tokyo, Japan: Tankousha.

Haglund, E. (1984). Japan: Cultural considerations. International Journal of Intercultural Relations, $\underline{8}$, 
$61-76$.

Hall, E. (1977). Beyond culture. Garden city, NY: Doubleday .

Hall, E. T., \& Hall, M. R. (1987). Hidden differences: Doing business with the Japanese. Garden City, NY: Anchor/Doubleday.

Hall, E. T., \& Whyte, W. F. (1979). Intercultural communication. In C. D. Motensen (Ed.). Basic readings in communication theory (pp. 403-419).

Harrigan, J. A. (1985). Listener's body movements and speaking turns. Communication Research. 12, 233-250.

HCI \& Reilly, J. V. (Eds.). (1991). Everything you ever wanted to know about business otsukiai. ( J. V. Reilly, Trans.). New York, NY: HCI Publications. (Original work published 1990)

Hecht, M. L., Anderson, P. A., \& Ribeau, S. A. (1990). The cultural dimension of nonverbal communication. In $M$. K. Asante \& W. B. Gudykunst (Eds.)., Handbook of international and intercultural communication. (pp. 163-203). Newbury Park, CA: Sage Publications, Inc.

Heider, F, (1958). The psychology of interpersonal relations. New York: John Wiley.

Hellweg, S. A., Samovar, L. A., \& Skow (1991). Cultural variations in negation styles. In L. A. Samovar \& R. E. Porter (Eds.), Intercultural communication: A reader (185-192). Belmont, CA: Wadsworth Publishing Company.

Hoebel, E. A. \& Frost, E. L. (1976). Culture and social anthropolooy. New York: McGraw-Hill.

Hoshi, I. (1987). Perspective on Japan and the West: The world of sex, Volume 3 : responsible parenthood. Woodchurch, Ashfold, Kent, England: Paul Norbury Publications Limited.

Hugh, D. D. (1968). Symbols in society. NY: Oxford University Press.

Ishii, S. \& Bruneau, T. (1991). Silence and silences in cross-cultural perspective: Japan and the United 
States. In L. A. Samovar \& R. E. Porter (Eds.), Intercultural communication: a reader. ( 6 th ed.). (pp. 314-319). Belmont, CA: Wadsworth Publishing Company, Inc.

Ishikawa, H. (1970). Chinmoku-gata wa shussesuru. [The silent type succeeds]. Mainichi-shinbun.

Jaksa, J. A. \& Stech, E. L. (1978). Communication to enhance silence: the trappist experience. Journal of communication, 28(1), 14-18.

Jaworski, A. (1993). The power of silence: social and pragmatic perspectives. Newbury Park, CA: Sage Publications.

Johannesen, R. L. (1974). The function of silence: a plea for communication research. Western Journal of Speech Communication, $\underline{23}, 25-35$.

Joseph, F., Hare, Jr. Andersen, Tatham, R. L. \& Block, W. C. (1992). Multidimensional data analysis. (3rd. ed.). New York: Macmilion Publishing Company.

Johnson, S. C. (1967). Hierarchical clustering schemas. Psychometrika, 32, 241-254.

Johnston, J. (1980). Business communication on Japan. The journal of Business Communication, 17, 65-70.

Kindaichi, H. (1975). Nihoijin no gengo hyougen. [Japanese verbal expressions]. Tokyo: Taishindo.

Kato, K. \& Rozman, M. (1991). Nichibei communication gaps: kotoba de saquru America. [Communication gaps between Japanese and Americans: The American mentality]. (rev. ed.). Japan: Japan Times Co.

Keene, D. (1990). Noh and Bunraku: Two forms of Japanese theater. Oxford, NY: Columbia university press.

Kelley, H. (1972). Attribution in social interaction. In E. E. Jones, D. E. Kanouse, H. H. Kelley, R. E. Nisbett, S. Valins, \& B. Weiner (Eds.). Attribution: perceiving the causes of behavior, (pp. 1-26). Morristown, NJ: General Learning Pree.

Kim, Y. Y. (1984). Searching for creative integration. In W. B. Gudykunst \& Y. Y. Kim (Eds.), Methods for 
intercultural communication research. Beverly Hills, CA: Sage Publishing Company.

. (1982). Toward an interactive theory of communication: Acculturation. In D. Nimmo (Ed.). Communication Yearbook, (pp. 435-453). NJ: Transaction Books.

Klopf, D. W. (1991). Japanese communication practices: recent comparative research. Communication Ouarterly, 39, $130-143$.

Knapp, M. L. (1972). Nonverbal communication in human interaction. New York, NY: Holt, Rinehart and Winston Inc.

Kroeber, A. L. \& Kluckhohn C. (1952). Culture: A critical review of concepts and definitions. Harvard university peabody museum of American archeoloay and ethnology papers, 47 .

Kruskal, J. B. \& Wish, M. (1976). Multidimensional Scaling. Newburry Park, CA: Sage publications.

Kumar, R. (1986). Cultural differences in negotiation behavior: the case of U.S. and Japan. Unpublished manuscript, College of Business Administration, Pennsylvania State University, Philadelphia.

Lebra Sugiyama, T. (1987). The cultural influence of silence in Japanese communication. Multilingual, 6-4, 343-357.

Lebo, R. J. (1959, February). Are You silent? Today's - Speech, 7, 3-4.

Lippard, P. V. (1988). The rhetoric of silence. Communication Ouarterly, 36, 145-156.

Littlejohn, s. W. (1989). Theories of human communication. (3rd. ed.). Belmont, CA: Wadsworth Publishing Company.

Longman dictionary of contemporary English (1984). Great Britain: The Pitman Press, Bath.

March, R. M. (1988). The Japanese negotiator: Subtlety and strategy beyond Western logic. Tokyo: Kodansha International. 
March, R. (1982, April). Melodrama in Japanese negotiations: Doing business in Japan requires a different kind of gamesmanship. Winds, pp. 23-29.

Mare, L. D. (1990). Ma and Japan. The Southern communication Journal, 55, 319-328.

Markel, N. N. (1969). Orientation. In N. N. Markel (Ed.), Psycholinguistics: an introduction to the study of speech and personality. (pp. 3-12). Homewood, IL: Dorsey Press.

Mclaughlin, M. L. (1984). Conversations: How talk is organized. Beverly Hills, CA: Sage Publications, Inc.

Meerloo, J. (1967). Contributions of psychiatry to the study of human communication. In F. E. X. Dance (Ed.), Human communication theory. (pp. 145-148). NY: Holt, Rinehart and Winston.

Midooka, K. (1990). Characteristics of Japanese-style communication. Media, Culture, and Society, 12 (4), 477-489.

Minami, H. (1983). Ma towa nanika. [What is 'ma']. In $\mathrm{H}$. Minami (Eds.). Ma no kenkyu. [The study of 'ma']. (pp. 7-22). Tokyo: Kodansha.

Moeran, B. D. (1981). Yanagi Muneyoshi and the Japanese folk craft movement. Asian folklore studies, 40(1), pp. 87-99.

Nakamura, H. (1964). Ways of thinking eastern peoples: India, China, Tibet, Japan. Honolulu, Hawaii: East West Center Press.

Nakata, Y. (1973). The art of Japanese calligraphy (A. Woodhul1, Trans.). New York, NY: Weatherhill, Tokyo, Japan: Heibonsha. (Original work published 1905).

Naotsuka, R. (1992). Oubeijin ga chinmokusurutoki. [When Westerners remain silent]. (rev. ed.). Japan:

Taishuukan shoten.

Nishida, H. (1989). Iitsurei de miru nichibei communication gaps. [Communication gaps between Japanese and Americans: In case studies]. Japan: Taishuukan shoten. 
Nishikawa, I. (1936). Floral art of Japan. Tokyo, Japan: Maruzen company, Ltd.

Oliver, R. T. (1971). Communication and culture in ancient India and China. NY: Syracuse University Press.

Okabe, R. (1983). Cultural assumptions of East and West: Japan and the United States. In W. B. Gudykunst (Eds.). Intercultural communication theory. (pp. 2145). Beverly Hills, CA: Sage Publishing. Inc.

Okakura, K (1929). Cha no hon [The book of Tea]. ( $H$. Muraoka, Trans.). Japan: Iwanami Bunko.

Ong, w. J. (1967). The presence of the word. New Heaven: Yale University.

Oyama, M. (1973). This is Karate. Tokyo, Japan: Japan Publication, Inc.

Paige, R. M., \& Martin, J. N. (1982, May). Ethical and theoretical issues in intercultural communication training. Paper presented at the meeting of the International Communication Association, Boston, MA.

Pearce, W. B., \& Cronen, V. (1980). Communication action, and meaning. New York, NY: Praeger Publishers.

Philipsen, G. (1990). Speaking "Like a Man" in Teamsterville: Cultural patterns of role enactment in an urban neighborhood. In D. Carbaugh (Ed.). Cultural communication and intercultural contact. (pp. 11-20). Hillsdale, NJ: Lawrence Erlbaum Associates, Publishers.

Pilgrim, R. B. (1986). Intervals ( $\mathrm{Na}$ ) in space and time foundations for a religion-aesthetic paradigm $n$ Japan. History of Religions, 24-25, 254-277. Quarterly, $\underline{46}, 32-53$

Ramsey, S. (1985). To hear one and understand ten: Nonverbal behavior in Japan. In L. S. Samovar \& R. E. Porter (Eds.). Intercultural Communication: A reader (4th ed.). (pp. 307-321). Belmont, CA: Wadsworth Publishing Company.

Ramsey, S., \& Birk, J. (1983). Preparation of North 
Americans for interaction with Japanese:

Consideration of language and communication style. In D. Landis \& R. W. Brislin (Eds.). Handbook of

intercultural training, Volume III: Area studies in intercultural training (pp. 227-259). New York, NY: Pergamon Press.

Reilly, L. R. (1989). Japan's complete fighting system: Shin Kage Ryu. Rutland, Vermont \& Tokyo, Japan: Charles E. Tuttle Company.

Ritchie, L. D., Baker, R., \& Good, L. T. (1993). The concept of knowledge in the social structure of reality. Paper submitted to International

Communication Association Information Systems Division.

Robbins, O., Devoe, S., \& Wiener, M. (1978). Social patterns of turn-taking: nonverbal regulations. Journal of communications, 28 (3), 38-46.

Rowland, D. (1985). Japanese business etiquette: A practice guide to success with the Japanese. New York, NY: A Waner Communication Company.

Samovar, L. A., \& Porter, R. E. (1991). Communication between cultures. Belmont, CA: Wadsworth Inc.

Saville-Troike, M. (1984). The ethnography of communication: an introduction. New York, NY: Basil Blackwell Inc.

(1985). The place of silence in an integrated theory of communication. In M. SavilleTroike \& D. Tannen (Eds). Perspectives of silence. (pp. 3-18). Norwood, NJ: Ablex Publishing Corporation.

Scott, R. L. (1972). Rhetoric and silence. Western Speech, 36, $146-158$.

- (1993). Dialectical tensions speaking and silence. The Ouarterly Journal of Speech, 79, 1-18.

Sekine, M. (1985). Ze-Ami and his theories of Noh drama. Great Britain:Colin Smythe Limited.

Sermol, M. D. (1983). Toward a phenomenological-based perspective of acculturation to scottish immiarants. 
Unpublished master's thesis, Portland State

University, Portland, OR.

Shimanoff, S. B. (1980). Communication rules: Theory and research. Beverly Hills, CA: Sage.

Shimizu, Y., \& Rosenfield, J. M. (1985). Masters of Japanese calligraphy: 8th-19th century. New Heaven, CT: Eastern Press.

Slavson, S. R. (1966). The phenomenology and dynamics of silence in psychotherapy groups. International Journal of Group Psychotherapy, 16, 395-404.

Soshitsu, S. (1979) . Chado: The Japanese way of tea. NY: John Weatherhill, Inc.

(1966). Urasenke chanoyu a beginner's

handbook. Kyoto, Japan: Urasenke Konnichian Library.

Stewart, E. C. (1971). American cultural pattern: A crosscultural perspective: Dimension of international, education: Number three. Unpublished manuscript, University of Pittsburgh, Pittsburgh, Pennsylvania.

Sullivan, J. J.. \& Kameda, N. (1982). The concept of profit and Japanese-American business communication problems. Journal of Business communication, 19, 3339 .

Tannen, D. (1985). Silence: Anything but. In M. SavilleTroike \& D. Tannen (Eds). Perspectives of silence. (pp. 93-111). Norwood, NJ: Ablex Publishing Corporation.

Ting-Toomey, S. (1991) Cross-cultural interpersonal communication: An introduction. In S. Ting-Toomey \& F. Korzenny (Eds). Cross-cultural interpersonal communication. (pp. 1-10). Newbury Park, CA: Sage Publications, Inc.

Wagatsuma, H. (1989). Nihonjin to Amerikajin kokoga oochigai. [Here are the big differences between Japanese and Americans.] Tokyo: Nesco

- (1984). Some cultural assumptions among the Japanese. Japan Quarterly, 31, 371-379.

Wagner, G. (1968). On the wisdom of words. Princeton, NJ: 
Van Nostrand.

Watanabe, S. (1990). Framing in american and Japanese group discussions. Unpublished doctoral dissertation, Georgetown University, Washington D.C., JG.

Weisman, A. D. (1955). Silence and psychotherapy. Psychiatry, 18, 241-260.

Weinstock, A. (1974). Some factors that related or accelerate the rate of acculturation. Human relations, 17, pp. 321-340.

Work, W. (1981). ERIC report: Communication across cultures. Communication education, 30 (2), 184-191.

Yamada, H. (1989). American and Japanese topic management strategies in business meetings. Unpublished doctoral dissertation, Georgetown University, Washington, D.C., JG

Yoshikawa, M. J. (1982, July). Japanese and American modes of communication and implications for managerial and organizational behavior. Paper presented at the meeting of the Second International conference, Japan, Yokohama.

Ze-Ami. \& Zenchiku. (1974). Kakyo. In A. Omote \& S. Kato (Eds.). Nihon shisoh taike, vol 26. Japan: Iwanami.

Zimmerman, M. (1985). How to do business with Japanese. NY: Random House, Inc. 3 
APPENDIX A

QUESTIONNAIRE (THE U.S.) 
A. Please complete in the following.

1. Age:

2. Sex: M F

3. Occupation: below) (pick from the subjects

Administration/Manager, Artist/musician, Homemaker Manufacturer/Blue collar, Clerical/Sales, Student Education, Military, Professional, Other

4. Education: yrs. (Yrs. beyond H.S.)

5. College Major: subjects below) (pick from the

Business / Fine \& Performing Arts / Math \& Science Social Science / Engineering / Humanities Professional / Other

6. Ethnicity: Japanese [ ] Reside in the U.S. for [ ] years Other Asian

European American

African-American Hispanic-American Other

7. Hove you practiced one of following Japanese cultural practices: tea ceremony, calligraphy, flower arrangement, or karate?

Yes [ ] No [ ]

If yes, please continue. If no, please move on to question B.

Tea ceremony

Yes [ ] No [ ]

If yes, how long? a. Less than 6 months

b. 6 months to less than 1 year

c. 1 year to less than 6 years

d. More than 6 years

Calligraphy Yes [ ] No [ ] 
If yes, how long? a. Less than 6 months

b. 6 months to less than 1 year

c. 1 year to less than 6 years

d. More than 6 years

Flower Arrangement Yes [ ] No [ ]

If yes, how long? a. Less than 6 months

b. 6 months to less than 1 year

c. 1 year to less than 6 years

d. More than 6 years

Karate

$$
\text { Yes [ ] No [ ] }
$$

If yes, how long? a. Less than 6 months

b. 6 months to less than 1 year

c. 1 year to less than 6 years

d. More than 6 years

B. What kind of hobby do you have (other than studying Japanese cultural practices)?

C. Sorting cards. You can make 1 to ten piles (A to J). Please DO NOT make more than 10 piles. (There is no priority among Alphabet.)

Please keep the pile as you have sorted when you finish sorting. You need to refer to them for the next question after this question.

Pile number $A$

Pile number B [

Pile number $\mathrm{C}$ [

Pile number $D$

Pile number $E$

Pile number $F$

Pile number $G$

Pile number $\mathrm{H}$

Pile number I [ 
Pile number $J$

E. Suppose you are in the following situation. Please pick up the pile that includes the most number of words relevant to each situation. You can simply write your pile letter (not pile number) into the blank.

a. Silence while deciding what to do during the holidays with your intimate friend.

$$
\text { Pile letter [ ] }
$$

b. Silence while negotiating the changing of your grade with your teacher.

$$
\text { Pile letter [ ] }
$$

c. Silence of your partner in front of you.

$$
\text { Pile letter [] }
$$

d. Silence of your boss at your work in front of you.

$$
\text { Pile letter [ ] }
$$

e. Silence of your father or mother in front of you.

$$
\text { Pile letter [ ] }
$$

f. Silence of your teacher during the class.

$$
\text { Pile letter [ ] }
$$

g. Silence of your same sex intimate friend in front of you.

h. Silence when you are alone.

$$
\begin{aligned}
& \text { Pile letter [ ] } \\
& \text { Pile letter [ ] }
\end{aligned}
$$

i. Silence when you are with a Japanese friend. (Please answer if you have a Japanese friend.)

Pile letter [ ]

j. Silence while you are practicing a Japanese cultural art such as calligraphy, tea ceremony, flower arrangement, or karate. 
APPENDIX B

KEY WORDS FOR CARDS SORT (THE U.S.) 
Pilot Study

(1) disagree

(2) agree

(3) passive

(4) compromise

(5) pondering

(6) figuring

(7) waiting for a turn to speak

(8) appropriate

(9) inappropriate

(10) conflict

(11) emotional

(12) save-face

(13) confused

(14) anxiety

(15) questioning

(16) doubtful

(17) warning

(18) threatening

(19) dislike

(20) dignity

(21) patience

(22) courage

(23) self-enlightenment

(24) spiritual

(25) intuition

(26) confident

(27) daydreaming

(28) preoccupied

(29) shared mood

(30) impolite

(31) polite

(32) reserved

(33) noncommittal attitude

(34) implicit

(35) indirect

(36) amae (interdependence)

(37) indecisive

(38) insight

\section{Main study}

(1) disagree

(2) agree

(3) passive

(4) insight

(5) pondering

(6) figuring

(7) waiting for a turn

(8) appropriate

(9) inappropriate

(10) conflict

(11) comfort

(12) save-face

(13) confused

(14) anxiety

(15) shy

(16) doubtful

(17) warning

(18) threatening

(19) dislike

(20) dignity

(21) patience

(22) tranquility

(23) self-enlightenment

(24) spiritual

(25) indecisive

(26) confident

(27) daydreaming

(28) preoccupied

(29) meditating

(30) impolite

(31) polite

(32) reserved

(33) noncommittal attitude (34) peaceful

(35) indirect 
APPENDIX C

TEN CONTEXTS (THE U.S.) 
1. Silence while deciding what to do during the holidays with your intimate friend.

2. Silence while negotiating the changing of your grade with your teacher.

3. Silence of your partner in front of you.

4. Silence of your boss at your work in front of you.

5. Silence of your father or mother in front of you.

6. Silence of your teacher during the class.

7. Silence of your same sex intimate friend in front of you.

8. Silence when you are alone.

9. Silence when you are with a Japanese friend. (Please answer if you have a Japanese friend.)

10. Silence while you are practicing a Japanese cultural art such as calligraphy, tea ceremony, flower arrangement, or karate. 
APPENDIX D

QUESTIONNAIRE (JAPANESE) 
就㷛に戌するアンケート

A．下記を、ご郡入ください。

1 年喤 「小歳

2 性别男「1 女下

3 i

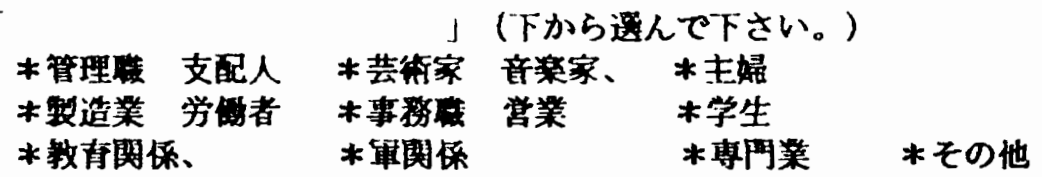

4 高校より上の教育年数「」年（高校 3 年間を除いた上）

5 大学での尃門科目「」(下から選んで下さい。)

*ヒジネス（经営、経済）*芸街学部 *理工科

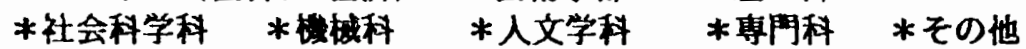

6 日本国籍ですか？はい「」いえ「」

7 米国での滞在期間は、どのくらいですか？
a. 6 力月末满
b. 6 ヶ月以上 から 1 年末满
c. 1 年以上 加 6 年末满
d. 6 年以上

8 花道、茶道、書道、空手のうちの一つでも習ったことがある人は、そのまま進んでく ださい。そうでない煦合 留問Bへ進んでください。

以下の 習い事をしたことがありますか？

茶道はい「いいえ「

はいの場合、とのくらい習いましたか？

a. 6 力月末满

b. 6 r月以上 加 1 年末满

c. 1 年以上 加 6 年末满

d. 6 年以上

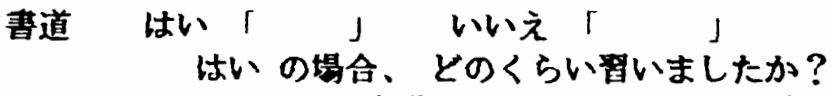

a. 6 力月未满

b. 6 万月以上 加 1年末渵

c. 1 年以上から 6 年末满

d. 6 年以上 
萧道はい「いいえ「

はいの围合、どのくい胃いましたか？

a. 6 力月末满

b. 6 肫上 加 1年末满

c. 1 年以上 加 6 年末满

d. 6 年以上

空手はい「いいた 」

はいの每合、とのくらい目いましたか？

a. 6 力月未苇

b. 6 ヶ月以上 から 1年末洴

c. 1 年以上 か5 6 年末满

d. 6 年以上

$\begin{array}{ll}r & j \\ r & j \\ r & j\end{array}$

B. とのようなた味をお持ちてすか（上記の酋い事の他に）？

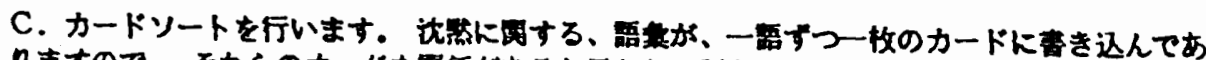

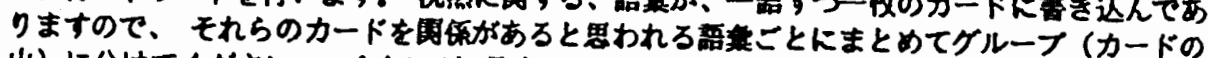

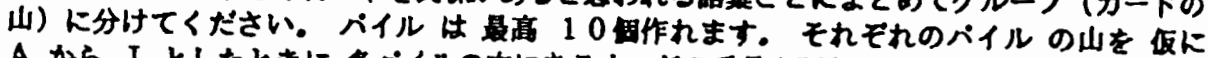

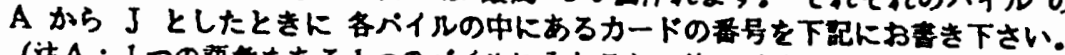

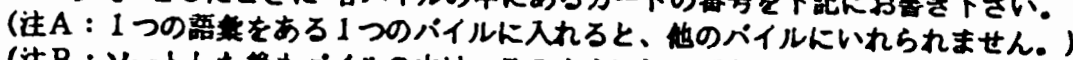

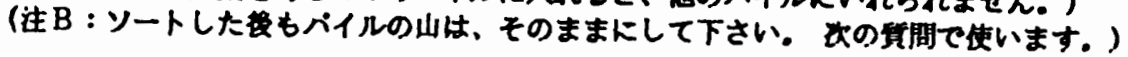

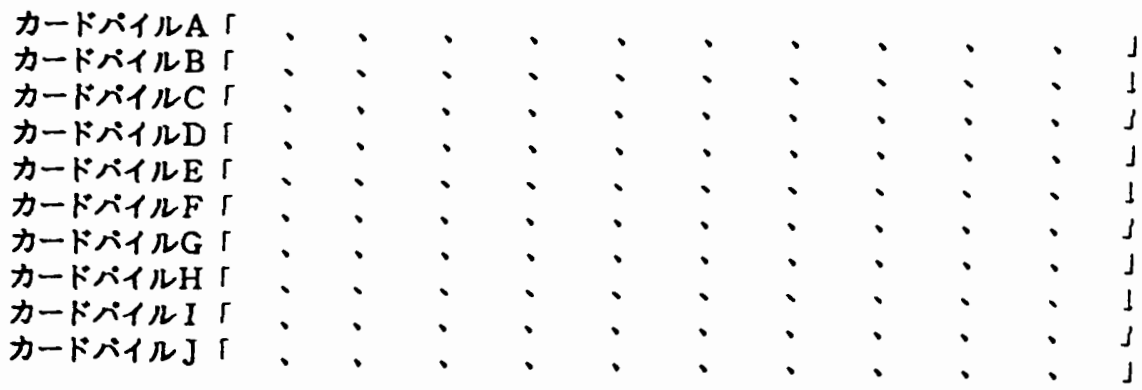

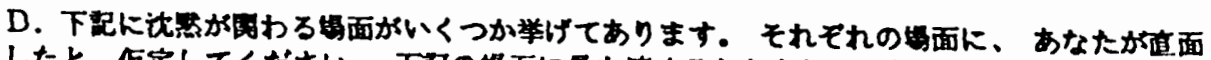

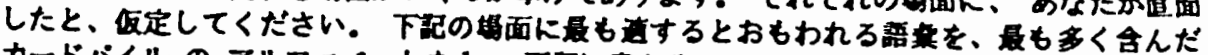
カードパイルの アルファケットを1つ下就に夆き込んでください。

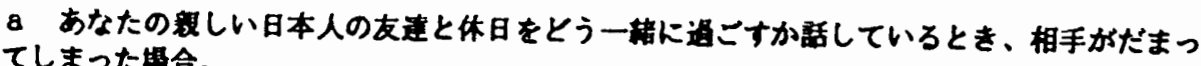
てしまった婄。

$$
\text { カート゚ペイルアルファペット「 }
$$

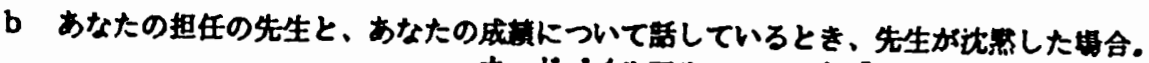

$$
\text { カードパイルアルファヘット「」 }
$$

c あなたと男女同俰にある相手が、あなたの前て沈梠したとを。 


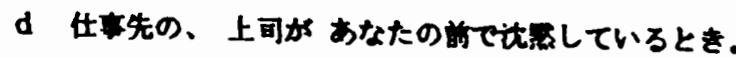

$$
\text { カードペイルアルファヘット「、」 }
$$

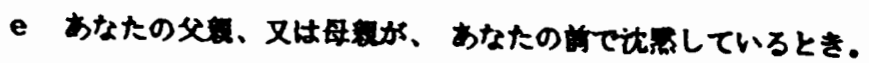

$$
\text { カードペイルアルファヘット「， }
$$

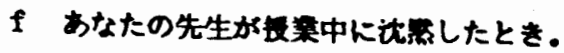

$$
\text { カードペイルアルファヘット「」 }
$$

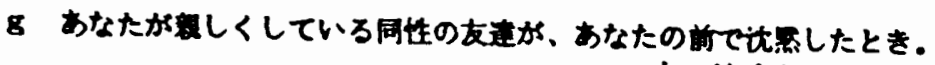

$$
\text { カードペイルアルフォヘット 「」 }
$$

h あなたが一人でいて、顼していろとき。

$$
\text { カードペイルアルファペト「「 }
$$

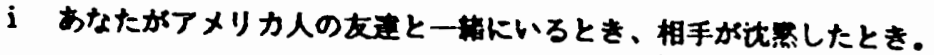

$$
\text { カードパイルアルファヘット「 }
$$

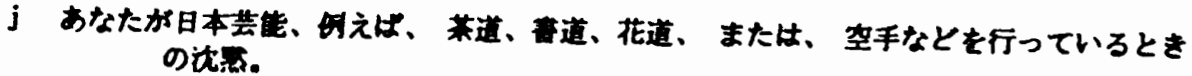

$$
\text { カードペイルアルファペゥト 」 }
$$


APPENDIX E

KEY WORDS FOR CARDS SORT (JAPANESE) 
氿然の解哂の仕方に関するリサーチでカードソートに使われたキーワートド

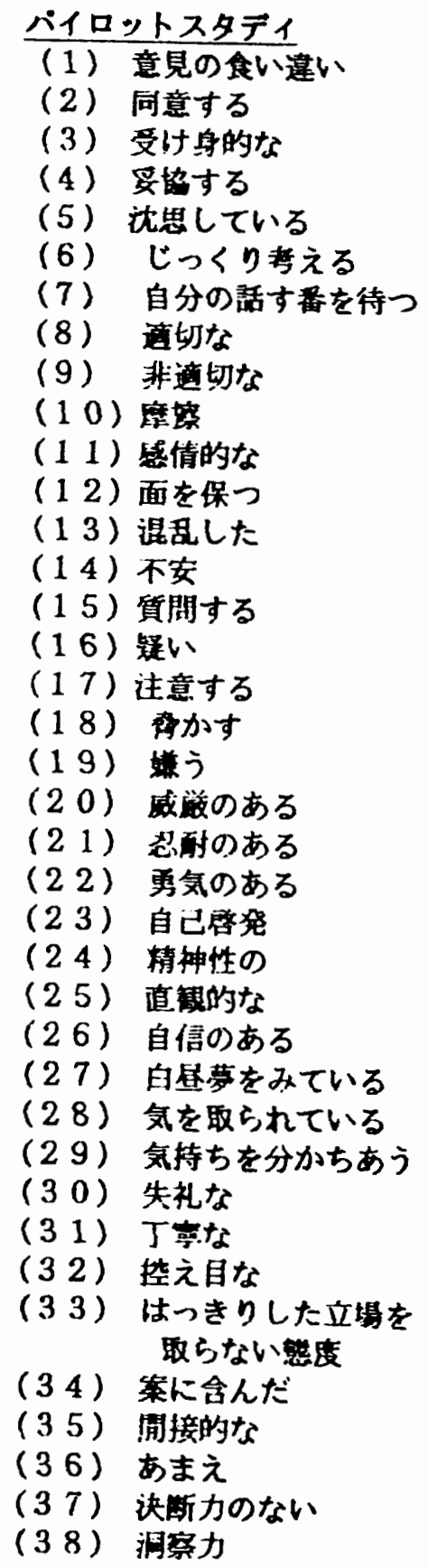

（7）自分の憇す番を待つ

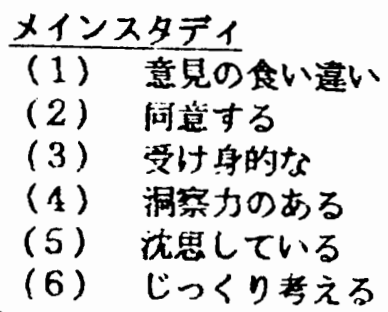


APPENDIX F

TEN CONTEXTS (JAPANESE) 
10 谓の坦面

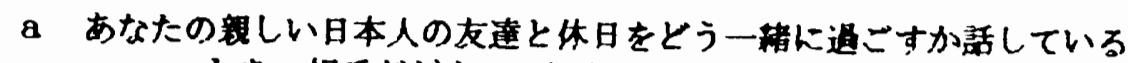
とき、相手がだまってしまった軥合。

b あなたの担任の先生と、あなたの成結について話しているとき、先生が 沈然した場合。

c あなたと男々関係にある相手が、あなたの前で就然したとき。

d 仕事先の、上司が あなたの前で沈然しているとき。

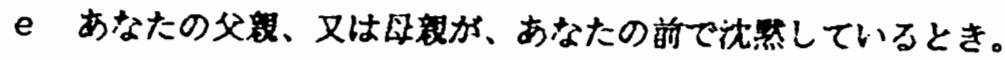

f あなたの先生が骎業中に氿然したとき。

g あなたが親しくしている同性の友逢が、あなたの前で沈然したとき。

hあなたが一人でいて、沈然しているとき。

i あなたがアメリカ人の友達と一粕にいるとき、相手が沈䇠したとき。

j あなたが日本芸能、田えば、余道、書道、花道、または、空手などを行っている ときの沈怔。 